\title{
Rhamnan Sulfate Reduces Atherosclerotic Plaque Formation and Vascular Inflammation
}

Nikita P. Patil ${ }^{* 1}$, Almudena Gómez-Hernández ${ }^{* 2}$, Fuming Zhang ${ }^{3}$, Limary Cancel $^{4}, \mathrm{Xu} \mathrm{Feng}^{1}$, Lufeng $\mathrm{Yan}^{3}, \mathrm{Ke} \mathrm{Xia}^{3}$, Eri Takematsu ${ }^{1}$, Emily Y. Yang${ }^{1}$, Victoria Le ${ }^{1}$, Megan E. Fisher ${ }^{1}$, Agueda Gonzalez-Rodriguez ${ }^{5}$, Carmelo Garcia-Monzon ${ }^{5}$, James Tunnell ${ }^{1}$, John Tarbell ${ }^{4}$, Robert J. Linhardt ${ }^{3}$ and Aaron B. Baker ${ }^{1,6,7,8}$

${ }^{1}$ Department of Biomedical Engineering, University of Texas at Austin, Austin, TX ${ }^{2}$ Department of Biochemistry and Molecular Biology, School of Pharmacy, Complutense University of Madrid, Madrid, Spain

${ }^{3}$ Departments of Chemistry and Chemical Biology, Chemical and Biological Engineering, Biology, and Biomedical Engineering, Center for Biotechnology and Interdisciplinary Studies, Rensselaer Polytechnic Institute, Troy, NY

${ }^{4}$ Department of Biomedical Engineering, The City College of New York, CUNY, New York, NY ${ }^{5}$ Liver Research Unit, Hospital Universitario Santa Cristina, Instituto de Investigación Sanitaria Hospital Universitario de La Princesa, CIBERehd, Madrid, Spain.

${ }^{6}$ Institute for Cellular and Molecular Biology, University of Texas at Austin, Austin, TX

${ }^{7}$ The Institute for Computational Engineering and Sciences, University of Texas at Austin, Austin, TX

${ }^{8}$ Institute for Biomaterials, Drug Delivery and Regenerative Medicine, University of Texas at Austin, Austin, TX

*Denotes equal contribution.

Total Figures: 6 main text figures +13 supplemental figures

Total Tables: 2

Running Title: Rhamnan sulfate reduces vascular plaque formation

Correspondence to:

Aaron B. Baker

University of Texas at Austin

Department of Biomedical Engineering

1 University Station

BME 5.202D, C0800

Austin, TX 78712

Phone: 512-232-7114

E-mail: abbaker1@gmail.com 


\section{Abstract}

Objective: While lipid-lowering drugs have become a mainstay of clinical therapy these treatments only slow the progression of the disease and can have side effects. Thus, new treatment options are needed to supplement the effects of lipid lowering therapy for treating atherosclerosis. We examined the use of an inexpensive and widely available marine polysaccharide rhamnan sulfate as an oral therapeutic for limiting vascular inflammation and atherosclerosis.

Methods and Results: We found rhamnan sulfate enhanced the barrier function of endothelial cells, preventing the deposition of LDL and maintaining barrier function even in the presence of glycocalyx-degrading enzymes. Rhamnan sulfate was also found to bind directly to FGF-2, PDGFBB and NF- $\mathrm{KB}$ subunits with high affinity. In addition, rhamnan sulfate was a potent inhibitor of NF- $\kappa B$ pathway activation in endothelial cells by TNF- $\alpha$. We treated $\mathrm{ApoE}^{-/-}$mice with a high fat diet for 4 weeks and then an addition 9 weeks of high fat diet with or without rhamnan sulfate. Rhamnan sulfate reduced vascular inflammation and atherosclerosis in both sexes of $\mathrm{ApoE}^{-/-}$mice but had a stronger therapeutic effect in female mice. Oral consumption of rhamnan sulfate induced a significant decrease in cholesterol plasma levels in female mice but not in male mice.

Conclusions: Rhamnan sulfate has beneficial effects in reducing inflammation, binding growth factors and NF-kB, enhancing endothelial barrier function and reducing atherosclerotic plaque formation in $\mathrm{ApoE}^{-/ /}$mice.

Keywords: rhamnan sulfate, marine polysaccharides, atherosclerosis, NF- $\mathrm{B}$ pathway, inflammation 


\section{Introduction}

Cardiovascular disease continues to be a major cause of mortality worldwide, with roughly 17 million people dying from cardiovascular disease worldwide each year and an associated healthcare cost of over $\$ 500$ billion in medical costs annually. Atherosclerosis is a chronic, progressive disease in which the accumulation of lipids, endothelial dysfunction and inflammatory processes within the vascular wall lead to plaque development.[1],[2] Atherosclerotic plaques underlie a many forms of vascular disease and can lead to organ ischemia, stroke and myocardial infarction. Pharmacotherapy with statins have become a mainstay of modern treatment of atherosclerosis but often only slow the inevitable progression of the disease and do not represent a cure for the vast majority of patients.[3, 4]

The endothelial glycocalyx is a layer of glycans that lines the interior of the artery and interacts with the flowing blood.[5] The endothelial glycocalyx provides an atheroprotective effect within the artery, in part by maintaining the endothelial barrier function that prevents lipid deposition, reduces inflammation, and lowers the risk of arteriothombosis.[6-8] During the progression of atherosclerotic disease, there is loss of the glycocalyx[9] and associated lipid deposition, and inflammation.[10, 11] Many of the major risk factors for atherosclerosis, including elevated C-reactive protein, hyperglycemia, oxidized lipids, and hyperlipidemia, lead to the depletion and degradation of the endothelial glycocalyx.[12-17] Major components of the glycocalyx include glycosaminoglycans, including heparan sulfate, chondroitin sulfate and hyaluronic acid. In the absence of these glycosaminoglycans, endothelial barrier function is compromised and immune cell adhesion is increased.[18-20]

Many marine product-derived polysaccharides have a structure roughly analogous to the polysaccharides in the glycocalyx and have oral bioavailability.[21, 22] Several of these compounds including laminarin sulfate and fucoidan have been explored as treatments for vascular disease and as anti-coagulants.[22] Sulfated polysaccharides specifically have exhibited antioxidant and anti-inflammatory properties making them potential therapeutics for atherosclerosis.[23] Rhamnan sulfate (RS) is a polysaccharide derived from green seaweeds including Monostroma nitidum. Rhamnan sulfate has a structure similar to endogenous glycosaminoglycans but is composed of a different backbone of polysaccharides which are primarily alpha-1,3-linked L-rhamnose residues that have sulfate groups. Thus, RS provides a rough approximation of the chemical structure of many of the glycans that compose the 
endogenous glycocalyx of the artery including that of heparan sulfate.[24] Rhamnan sulfate has been shown to decrease inflammation in vascular endothelial cells in vitro and inhibit hepatic lipogenesis in a zebrafish model.[25, 26] Previous studies from our group indicate that RS has some anti-inflammatory properties and oral bioavailability. These properties make RS a promising candidate as an oral treatment for atherosclerosis.

In this work, we examined the use of highly purified RS as a potential therapy for plaque development and vascular inflammation. Our work demonstrates that RS has an anti-inflammatory effect on endothelial cells, can bind to NF- $\kappa \mathrm{B}$ and inhibit inflammatory signaling. In addition, we found that RS can directly bind to PDGF-BB and inhibit its effects on vascular smooth muscle cell (vSMC) migration and proliferation. We further tested RS as an oral therapy for atherosclerosis in male and female $\mathrm{ApoE}^{-/-}$mice. We found that RS reduced atherosclerosis in both sexes, but it had stronger lipid lowering and anti-inflammatory effects on female mice in comparison to male mice. Taken together, our results support that RS has potential as an inexpensive oral treatment for atherosclerosis. 


\section{Methods}

Cell culture. Human umbilical vein endothelial cells (HUVECs) were purchased from PromoCell. They were grown in MCDB-131 culture medium (Life Technologies) with EGM-2 growth factors (R\&D Systems), 10\% fetal bovine serum (FBS), L-glutamine and antibiotics. Human aortic smooth muscle cells (HAoSMCs) were grown in MCDB-131 culture medium (Life Technologies) with $10 \%$ FBS, L-glutamine and antibiotics. Cells were received at passage 2 and were not allowed to grow past passage 8 . Human coronary artery endothelial cells (HCAEC) were purchased and grown in cell specific growth medium according to the manufacturer's instructions (Cell Applications). All cells were grown at $37^{\circ} \mathrm{C}$ with $5 \% \mathrm{CO}_{2}$.

Rhamnan sulfate purification/analysis. Rhamnan sulfate was isolated from green seaweed (Monostroma nitidium sourced from Japan) powder using methods described previously.[27] The powder was homogenized in distilled water (1:30 seaweed:water) and extraction was performed at $100^{\circ} \mathrm{C}$ for three hours. The extract was centrifuged at $4700 \mathrm{~g}$ for $10 \mathrm{~min}$ and the supernatant was collected. Ethanol was added to the supernatant to achieve $80 \%$ ethanol per total volume. Crude polysaccharide was precipitated from the supernatant with three volumes of anhydrous ethanol and dissolved in distilled water. The polysaccharide solution was dialyzed in a cellulose membrane (molecular weight cut-off of $3500 \mathrm{Da}$ ) against distilled water for three successive days. After dialysis, the RS was lyophilized and weighed. Molecular weight of a monomer of RS was 150 $\mathrm{kDa}$, measured after purification, and the aggregate in $1 \mathrm{mg} / \mathrm{mL}$ solution was estimated to be $2.67 \times 10^{7} \mathrm{kDa}$ using DLS.

Labeling of RS with FITC. Labeling and detection of RS with FITC was performed as described previously.[28] Briefly, the polysaccharide was activated by adding $\mathrm{CNBr}(8.33 \mathrm{mg} / \mathrm{mL})$ to RS $(20 \mathrm{mg} / \mathrm{mL})$ with the mixture maintained at $\mathrm{pH} 11$. Activated RS was desalted using a $20 \mathrm{~cm}$ Sephadex G-50 column in $0.2 \mathrm{M}$ sodium borate ( $\mathrm{pH}$ 8.0). The RS containing fractions were pooled and reacted with $2 \mathrm{mg}$ fluoresceinamine. Gel filtration was used to separate RS-FITC from unreacted fluoresceinamine and the concentration of fluorescein determined by reading absorbance at $440 \mathrm{~nm}$. Concentration of RS was determined using the phenolsulfuric acid method. Degree of addition was expressed as moles of fluorescein per mole of monosaccharide and molecules of fluorescein per polysaccharide molecule. 
Inhibition of uptake pathways. Endothelial and vascular smooth muscle cells were grown to confluence in MCDB-131 medium as described earlier. To prevent mitosis, mitomycin $(1 \mathrm{mg} / \mathrm{mL}$; Sigma-Aldrich) was added to the cells, with no treatment cells as control. To prevent uptake through the caveolin mediated endocytosis pathway, nystatin ( $1 \mathrm{mg} / \mathrm{mL}$; Thermo Fisher Scientific) was added to the cells, using DMSO $(1 \mathrm{mg} / \mathrm{mL})$ for control. Pitstop 2 and pitstop 2 negative control $(1 \mathrm{mg} / \mathrm{mL}$; Abcam) were added to both cell types to prevent uptake through the clathrin mediated endocytosis pathway. Rottlerin (1 mg/mL; Santa Cruz Biotechnology) and DMSO control were used to test for inhibition of macropinocytosis. All groups received $1 \mathrm{mg} / \mathrm{mL}$ RS labeled with FITC. Cells were fixed after treatments for 24,48 and $72 \mathrm{~h}$, stained with DAPI and imaged using a confocal microscope.

Proliferation and migration assays. To measure proliferation, cells were seeded on a fibronectin coated 96-well plate and grown to confluence. They were starved with 0.5\% FBS medium for 24 hours, then treated with RS (100 or $1000 \mu \mathrm{g} / \mathrm{mL})$ and growth factors (10 ng/mL PDGF-BB or FGF-2) for 72 hours. Proliferation was measured using the BrdU Cell Proliferation Assay Kit (Cell Signaling Technology). Migration was measured using the ORIS Cell Migration Assay Kit (Platypus Technologies). Cells were seeded on a fibronectin coated ORIS plate and grown to confluence. The cells were then placed in media with $0.5 \%$ FBS for 24 hours. The stoppers were removed, and the cells were treated with RS (100 or $1000 \mu \mathrm{g} / \mathrm{mL})$ and growth factors $(10 \mathrm{ng} / \mathrm{mL}$ PDGF-BB or FGF-2). Images of each well were captured every 24 hours for the duration of the experiment using a Cytation 5 Cell Imaging Multi-Mode Reader (BioTek).

LDL permeability assay. Human coronary artery endothelial cells at passages 4-8 were plated onto fibronectin coated Transwell membranes ( $12 \mathrm{~mm}$ diameter, $0.4 \mu \mathrm{m}$ pores, Corning) at a density of $0.5 \times 10^{4}$ cells $/ \mathrm{cm}^{2}$. Cells reached confluence within 2-3 days after plating, and experiments were carried out on monolayers 4-6 days post-plating. Immediately before the start of an experiment the media was changed to the experimental media consisting of phenol-red free basal media (Cell Applications) supplemented with 1\% bovine serum albumin (BSA; Sigma-Aldrich). For studies with treatments, the HCAECs were incubated with growth media (control) or growth media containing RS at $25 \mu \mathrm{g} / \mathrm{mL}$ for $24 \mathrm{~h}$, followed by a $2 \mathrm{~h}$ incubation with Heparinase III (HepIII; 
Ibex pharmaceuticals, Quebec, Canada) at $135 \mathrm{mU} / \mathrm{mL}$ or $1215 \mathrm{mU} / \mathrm{mL}$ in experimental media. After the $2 \mathrm{~h}$ HepIII treatment, HCAECs were rinsed twice with experimental media and the permeability of DiI-LDL was measured. Tumor necrosis factor alpha (TNF- $\alpha, 20 \mathrm{ng} / \mathrm{mL}$; SigmaAldrich) and cycloheximide (chx, $3 \mathrm{mg} / \mathrm{mL}$; Sigma-Aldrich) were used to induce elevated apoptosis and permeability.[29] The cells were grown for 5 days before incubation with TNF- $\alpha$ and chx (TNF- $\alpha / \operatorname{chx})$ in the presence or absence of the RS isoforms or heparin $(100 \mu \mathrm{g} / \mathrm{mL}$; SigmaAldrich). TNF- $\alpha / \mathrm{chx}$ was removed after $3.5 \mathrm{~h}$ of incubation and the cells were allowed to recover for $20 \mathrm{~h}$ in the presence or absence of RS or heparin.

The experimental apparatus used for measurement of LDL was as described previously.[29, 30] The apparatus consists of eight Delrin ${ }^{\circledR}$ chambers, each connected to a laser excitation source and an emission detector. A Transwell filter containing the HCAEC monolayer was inserted and sealed within the transport chamber creating a luminal (top) and abluminal (bottom) compartment. At the beginning of each experiment DiI-LDL ( $5 \mathrm{mg} / \mathrm{mL}$; Biomedical Technologies) was added to the luminal compartment. The fluorescent detection system was then used to measure the solute concentration in the abluminal compartment of each chamber as a function of time. Each transport experiment consisted of a one-hour equilibration period, followed by application of a $10 \mathrm{~cm} \mathrm{H}_{2} \mathrm{O}$ pressure differential and data collection for one hour. The permeability was calculated as

$$
P_{e}=\frac{V_{a}}{A C_{l}} \frac{\Delta C_{a}}{\Delta t}
$$

where $\Delta C_{a} / \Delta t$ is the change in the abluminal concentration with respect to time, $V_{a}$ is the fluid volume in the abluminal compartment, $C_{1}$ is the concentration in the luminal compartment, and $A$ is the area of the filter.

Immunostaining of heparan sulfate. Monolayers of HCAEC grown in Transwell membranes were stained for heparan sulfate using mouse monoclonal anti-heparan sulfate antibody (10E4 epitope, 1:100 in 2\% goat serum, AMSBIO) following previously established protocols.[31] Briefly, monolayers were fixed in $2 \%$ paraformaldehyde and $0.1 \%$ glutaraldehyde in PBS for 30 min, blocked with $2 \%$ GS for 30 min, and incubated with primary antibody overnight at $4{ }^{\circ} \mathrm{C}$ in a humidified chamber. Monolayers were then rinsed and incubated with secondary antibody Alexa Fluor 488 goat anti-mouse $\operatorname{IgG}(1: 300$ in $2 \%$ GS) for one hour at room temperature, and 
counterstained with DAPI. The stained monolayers were imaged using a ZEISS LSM 510 confocal microscope. ImageJ was used to quantify image intensity. The coverage of heparan sulfate was analyzed using the methods described in previous work.[31]

Preparation of subendothelial matrix samples. Monolayers of HCAECs were grown for 14 days in Transwell filters before the cells were removed by a method shown to leave intact subendothelial matrix attached to the Transwell.[32] Briefly, the monolayers were washed three times in PBS, incubated in $20 \mathrm{mM} \mathrm{NH}_{4} \mathrm{OH}$ in $0.1 \%$ Triton $\mathrm{X}-100$ for $5 \mathrm{~min}$ at room temperature, washed three times in PBS, and washed three times in basal media containing 3\% BSA. The filters with subendothelial matrix were then incubated with RS for $24 \mathrm{~h}$, and the permeability of the subendothelial matrix to DiI-LDL was measured.

Nuclear fractionation and extraction of proteins. Endothelial cells were maintained in MCDB131 medium with $0.5 \%$ FBS for at least $18 \mathrm{~h}$, then stimulated with TNF- $\alpha(10 \mathrm{ng} / \mathrm{mL})$ for 30 minutes with or without RS pretreatment for $24 \mathrm{~h}(100-500 \mu \mathrm{g} / \mathrm{mL})$. Tissue homogenates of endothelial cells were resuspended in a buffer, which consisted of $10 \mathrm{mM}$ HEPES (pH 7.8), 15 $\mathrm{mM} \mathrm{KCl}, 2 \mathrm{mM} \mathrm{MgCl} 2,0.1 \mathrm{mM}$ EDTA, $1 \mathrm{mM}$ dithiotheitol (DTT), and $1 \mathrm{mM}$ phenylmethylsulfonyl fluoride. After $10 \mathrm{~min}$ on ice, the tissue homogenates were pelleted and resuspended in two volumes of the buffer. Then, $3 \mathrm{M} \mathrm{KCl}$ was added dropwise to reach a $0.39 \mathrm{M}$ $\mathrm{KCl}$ concentration. We extracted the nuclei from the cells with incubation for $1 \mathrm{~h}$ at $4^{\circ} \mathrm{C}$ followed by centrifuged at $12,000 \mathrm{~g}$ for $1 \mathrm{~h}$. The supernatants were then dialyzed in a buffer, which consisted of $50 \mathrm{mM}$ HEPES ( $\mathrm{pH} 7.8), 50 \mathrm{mM} \mathrm{KCl}, 0.1 \mathrm{mM}$ EDTA, $1 \mathrm{mM}$ DTT, and $1 \mathrm{mM}$ phenylmethylsulfonyl fluoride with $10 \%(\mathrm{v} / \mathrm{v})$ glycerol. The samples were then cleared by centrifugation and stored at $-80^{\circ} \mathrm{C}$ until further use. Total protein concentration was determined by BCA (Thermo Fisher Scientific). We analyzed the levels and phosphorylation of I $\mathrm{B} \alpha$, IKK $\alpha$ and IKK $\beta$ in cytosolic fractions by western blotting as described below. We measured p65 in the nuclear and cytosol fractions by Western blot studies. We used $\beta$-actin and Histone H3 as control for total protein in cytosolic or nuclear fractions. The activity of $N F-\kappa B$ in binding DNA was assessed in nuclear fractions by a DNA Binding TransAM NF-кBp65 Assay (Active Motif). 
Western blotting. Cells were lysed using RIPA lysis buffer with added protease and phosphatase inhibitors $(10 \mu \mathrm{L} / \mathrm{mL})$, EDTA $(10 \mu \mathrm{L} / \mathrm{mL})$ and phenylmethylsulfonyl fluoride $(1 \mathrm{mM})$ (Thermo Fisher Scientific). They were sonicated for three minutes and then centrifuged at $10000 \mathrm{~g}$ for 10 minutes to collect total protein fraction. Concentration was determined using the Pierce BCA Protein Assay (Thermo Fisher Scientific). We performed SDS PAGE on the samples using the Invitrogen NuPAGE Bis- Tris protein gels. The proteins were transferred to nitrocellulose membranes using the wet transfer method (BioRad). The membranes were blocked with $4 \%$ StartingBlock T20 Blocking Buffer (Thermo Fisher Scientific) with 0.1\% Tween-20 in PBS or TBS for one hour. The membranes were then incubated with the primary antibodies in $1 \%$ StartingBlock overnight at $4^{\circ} \mathrm{C}$ (Supplemental Table 1). The membranes were then incubated with HP conjugated secondary antibodies (Cell Signaling) at 1:3500 dilution for two hours in 1\% Blotto. SuperSignal West Femto ECL solution (Thermo Fisher Scientific) was used to detect the antibodies and imaging was performed on a G:BOX imaging system (Syngene, Inc.).

Murine model of atherosclerosis. All animal studies were performed with the approval of the University of Texas at Austin Institutional Animal Care and Use Committee (IACUC) and in accordance with NIH guidelines "Guide for Care and Use of Laboratory Animals" for animal care.

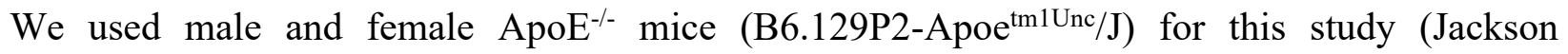
Laboratories, Inc.). The animals were given high fat chow which was the standard formulation Clinton/Cybulsky high fat rodent diet with regular casein and 1.25\% added cholesterol (D12108C; Research Diets, Inc.). For RS treated animals, the high fat diet (HFD) was formulated with $0.75 \mathrm{~g}$ of RS per kg diet. At 12 weeks of age, the mice were switched from normal chow to high fat chow for 4 weeks. The HFD group remained on this diet for an additional 9 weeks while the treatment group was switched to high fat chow with RS. At 4, and 12 weeks after start of HFD, the vessels of the mice were imaged using high resolution ultrasound as described below. At 13 weeks of HFD, the mice were sacrificed, and the blood, heart, aorta, liver and white adipose tissues were harvested for further analysis. For control, we used male and female wild type mice $(n=5)$ fed a standard diet for 13 weeks.

High resolution ultrasound imaging. High resolution ultrasound was performed using the Visual Sonics VEVO 2100 system with the MS500D transducer in the $\mathrm{ApoE}^{-/-}$model. The mice were 
anesthetized with isoflurane and body temperature monitored using a probe. Prior to imaging, the fur on the chest was removed using Nair. First, the longitudinal section of the aortic arch was located using the B-mode option. Pulsed wave Doppler and 3D echocardiography images were then obtained for calculating peak systolic velocity (PSV), end diastolic velocity (EDV) and, mean velocity (MV). The longitudinal section of the left common carotid artery was located using Bmode and pulsed wave Doppler images were obtained for the same parameters in the carotid artery. Finally, the cross section of the aortic arch was imaged in B-mode and color Doppler. Diameter measurements of the aortic arch determined from cross sections were used to calculate circumferential strain using the following formula:

$$
\frac{1}{2}\left(\left(\frac{\text { Sys }}{D i a}\right)^{2}-1\right) * 100
$$

Where sys and dia are the peak systolic and end diastolic diameters.

Histological staining. Aortic roots at optimal cutting temperature were embedded in NEG-50 and cut into $7 \mu \mathrm{m}$ thick sections using a cryostat (CM1510 S; Leica). These sections were stained with Oil Red O/hematoxylin to measure lipid depot using the protocol below. Individual lesion area was determined by averaging the maximal values. For the liver samples, the tissues were placed in NEG-50 embedding medium and then frozen in liquid nitrogen cooled isopentane. The samples were serially sectioned to create $7 \mu \mathrm{m}$ thick cryosections and Oil Red-O staining was performed. For the fat tissues, white adipose tissues (gonadal and inguinal depots) were fixed overnight in 4\% formaldehyde and paraffin sections were created using standard methods. The size of adipocytes in white adipose tissues were quantified in H\&E staining using Image J software.

Oil Red-O staining. A stock Oil Red O (Electron Microscopy Sciences) solution was made with $3 \mathrm{mg} / \mathrm{mL}$ Oil Red O in 99\% isopropanol. The stock was diluted in a 3:2 ratio in ultrapure water. Frozen cryosections were air dried and then fixed in 10\% formalin. They were stained with Oil Red $\mathrm{O}$ and counterstained with Mayer's hematoxylin (Electron Microscopy Sciences). The sections were mounted with aqueous mounting medium for imaging (Vector Labs).

Immunostaining for tissues. Lesional macrophages (F4/80), vSMCs ( $\alpha$-SMA), PECAM-1, eNOS, I $\mathrm{B} \alpha$ and p-p65 were detected by immunoperoxidase or immunofluorescence (Supplemental 
Table 1). Positive staining was expressed as percentage of total plaque area or number of positive cells per lesion area. In each experiment, negative controls without the primary antibody or using a nonrelated antibody were included to check for nonspecific staining.

En face imaging of aorta. Atherosclerotic lesions were quantified by en face analysis of the whole aorta. For en face preparations, the aorta was opened longitudinally, from the heart to the iliac arteries, while still attached to the heart and major branching arteries in the body. The aorta from the heart to the iliac bifurcation was then removed and was pinned out on a white wax surface in a dissecting pan using stainless steel pins $0.2 \mathrm{~mm}$ in diameter. After overnight fixation with $4 \%$ paraformaldehyde and a rinse in PBS, the aortas were immersed for $6 \mathrm{~min}$ in a filtered solution containing $0.5 \%$ Oil Red-O, 35\% ethanol and 50\% acetone and destained in $80 \%$ ethanol. The Oil Red-O stained aortas were photographed, and the atherosclerotic lesions were quantified using IP Win32 v4.5 software.

Pharmacokinetics of rhamnan sulfate in vivo. To test for oral bioavailability of RS, male mice (C57BL/6; Jackson Labs) were given RS-FITC (0.25 g RS/kg mouse) though oral gavage. Mice were sacrificed at the time points of $0,1,4,12$ and 24 hours $(n=2)$, and blood, aorta, liver and heart were harvested. The tissue samples were lysed and RS-FITC concentration measured by reading fluorescence intensity with correction for background fluorescence. A calibration curve was made for RS-FITC in each tissue to convert fluorescence to concentration.

To measure the half-life of RS in the blood a mouse was injected intravenously via the tail vein with $0.5 \mathrm{mg}$ of FITC conjugated RS (FITC-RS). A $10 \mathrm{ml}$ blood sample was collected from the saphenous vein 1 minute after injection, and then every five minutes for 25 minutes. The blood samples were centrifuged at 12,000 rpm for 5 minutes and the plasma was used for fluorescence measurements. Fluorescence intensity was measured using a plate reader (BioTek). A calibration curve for FITC-RS in mouse plasma was created which allowed the conversion of fluorescence intensity into concentration. The plasma concentration data was fitted to an exponential (first order elimination process is assumed). Extrapolating from the resulting equation we estimate the concentration at $\mathrm{t}=0$ is $0.278 \mathrm{mg} / \mathrm{mL}$. The apparent volume of distribution, $\mathrm{V}_{\mathrm{D}}$, is calculated from the relationship $V_{D}=$ Dose $/ C_{p}{ }_{p}$, where $C_{p}{ }^{0}$ is the concentration at $t=0$. We calculated $V_{D}$ to be $1.8 \mathrm{~mL}$. This is approximately equal to the blood volume (the blood volume of a mouse is $77-80$ 
$\mathrm{mL} / \mathrm{g})$. The half-life was calculated from the elimination rate constant $\left(t_{1 / 2}=\frac{\ln 2}{k}\right)$. With the data above, $\left(\mathrm{k}=0.0328 \mathrm{~min}^{-1}\right)$ the half-life is 21.1 minutes. Extrapolating from the data, the concentration drops below the lowest effective concentration we have tested $(1 \mathrm{mg} / \mathrm{mL})$ after 170 minutes.

Raman spectroscopy. Raman imaging was performed using a custom built 830nm confocal Raman microscope with a $60 \mathrm{x}$ water immersion objective (NA $=1.2$; Olympus).[33] The scattered light was collected by a spectrograph and a CCD camera though a $50 \mu \mathrm{m}$ core diameter fiber, which also acts as the pinhole of the confocal system. Fresh sections with $10 \mu \mathrm{m}$ thickness were mounted on low-background Raman substrates (magnesium fluoride window or quartz slide) for Raman imaging. For every animal, one liver section was prepared, and $2-5$ regions of interest were randomly selected from each section. Raman imaging was performed with a 0.25 or $0.5 \mathrm{~s}$ integration time and a step size of 0.75 or $1 \mu \mathrm{m}$. Image size varied from $24 \times 24 \mu \mathrm{m}^{2}$ to $40 \times 40$ $\mu^{2}$. Data preprocessing was performed using MATLAB (R2017a, MathWorks). Preprocessing steps included wavenumber calibration, background removal, cosmic ray removal, smoothing, and fluorescence background removal. Spectra were normalized to the area under the curve between 600 and $1800 \mathrm{~cm}^{-1}$. Cluster analysis was performed for each image by k-means algorithm.[34] The first 100 principal components accounting for $95 \%$ - 99\% of the variation in the data set served as the input for the k-means. Each image contained at most three clusters, annotated as the lipid-rich zone, protein-rich zone, and others. Only the spectra within the lipid-rich zone were extracted to calculate the degree of unsaturation. The average Raman spectrum of the lipid-rich zone was compared between different groups. The degree of unsaturation was calculated by the peak ratio of $1656 \mathrm{~cm}^{-1}$ (integrated from $1645-1675 \mathrm{~cm}^{-1}$ ) to $1441 \mathrm{~cm}^{-1}$ (integrated from $1420-1480 \mathrm{~cm}^{-}$ ${ }^{1}$ ), which corresponds to the ratio of $\mathrm{C}=\mathrm{C}$ stretching vibration and the band related to the $\mathrm{CH}_{2}$ scissoring mode.[34, 35]

Preparation of rhamnan sulfate and heparin biochip. Biotinylated RS or heparin was prepared by conjugating the reducing end to amine-PEG3-Biotin (Pierce).[36] In brief, RS or heparin (2 mg) and amine-PEG3-Biotin (2 mg, Pierce) were dissolved in $200 \mu 1 \mathrm{H}_{2} \mathrm{O}$ and $10 \mathrm{mg} \mathrm{NaCNBH}$ was added. The reaction mixture was heated at $70{ }^{\circ} \mathrm{C}$ for $24 \mathrm{~h}$, after that a further $10 \mathrm{mg} \mathrm{NaCNBH}$ 
was added and the reaction was heated at $70{ }^{\circ} \mathrm{C}$ for another $24 \mathrm{~h}$. After cooling to room temperature, the mixture was desalted with the spin column $(3,000 \mathrm{MWCO})$. Biotinylated RS or heparin was collected, freeze-dried and used for surface plasmon resonance (SPR) chip preparation. The biotinylated RS or heparin was immobilized to a streptavidin chip (GE Healthcare) based on the manufacturer's protocol. Successful immobilization of RS or heparin was confirmed by the observation of about 100 resonance unit (RU) increase on the sensor surface after $20 \mu \mathrm{l}$ injection of RS or heparin $(1 \mathrm{mg} / \mathrm{mL})$. The control flow cell was prepared by 1 min injection with saturated biotin.

Surface plasmon resonance of binding between rhamnan sulfate and proteins. Recombinant human FGF-1 and FGF-2 were a gift from Amgen. We purchased human antithrombin III (AT) (Hyphen Biomed), recombinant human platelet-derived growth factor (PDGF-BB), NF-кB p50, and NF-кB p65 (Abcam). The interactions between RS and proteins were measured using the BIAcore 3000 SPR system (GE Healthcare). The protein samples were diluted in HBS-EP buffer (0.01 M HEPES, 0.15 M NaCl, 3 mM EDTA, 0.005\% surfactant P20, pH 7.4). Different dilutions of protein samples were injected at a flow rate of $30 \mu \mathrm{L} / \mathrm{min}$. At the end of the sample injection, HBS-EP buffer was flowed over the sensor surface to facilitate dissociation. After a $3 \mathrm{~min}$ dissociation time, $30 \mu \mathrm{L}$ of $2 \mathrm{M} \mathrm{NaCl}$ was injected to fully regenerate the surface. The response was monitored as a function of time (sensorgram) at $25^{\circ} \mathrm{C}$.

Statistical analysis. All results are shown as mean \pm standard error of the mean. Comparisons between only two groups were performed using a 2-tailed Student's t-test. Multiple comparisons between groups were analyzed by 2-way ANOVA followed by a Tukey post-hoc test. A 2-tailed probability value $p<0.05$ was considered statistically significant.

\section{Results}

Rhamnan sulfate is internalized by macropinocytosis and is dependent on proliferation on vSMCs. To examine the kinetics of uptake of RS by vascular cells, we incubated endothelial cells and aortic vSMCs with FITC-labeled RS. We found that RS was detectable after 24 hours and that there was nuclear fluorescence from the RS after 48 hours (Fig. 1A, B). Based on the timing of the nuclear localization of RS, we hypothesized that RS was entering the nucleus during the 
disassembly and reassembly of the nuclear envelope during cell division. To test this hypothesis, we mitotically arrested cells using mitomycin and measures RS uptake. In vSMCs, mitomycin significantly inhibited the uptake and nuclear localization of RS (Fig. 1C). However, this effect was not seen in endothelial cells (Fig. 1D). We also treated the cells with inhibitors of caveolinmediated endocytosis (nystatin) and clathrin-mediated endocytosis (Pitstop 2) but neither had clear inhibitory effects on RS uptake (Fig. 1E-H). In contrast, treatment with an inhibitor of macropinocytosis (rottlerin) significantly inhibited uptake of RS in both endothelial cells and vSMCs (Fig. 1I, J).

Rhamnan sulfate decreases proliferation and migration of vascular cells. The proliferation and migration of vSMCs in atherosclerosis and vascular injury is an important mechanism in the development of intimal hyperplasia and remodeling of atherosclerotic plaques.[37] Endothelial proliferation and migration can be beneficial in vascular healing and reendothelialization following endothelial denudation.[38] However, these processes are also important for plaque neovascularization, which may have a role in thromboembolism and plaque destabilization.[39] We treated endothelial cell and vSMCs with RS and assayed their proliferation and migration in response to growth factors. Treatment with RS significantly reduced proliferation and migration of endothelial cells treated with FGF-2 (Fig. 2A-C). In vSMCs, RS decreased proliferation and migration in response to PDGF-BB (Fig. 2D-F). We also found that RS binds with high affinity to FGF-2 $\left(\mathrm{K}_{\mathrm{D}}=2.6 \times 10^{-8} \mathrm{M}\right)$ and PDGF-BB $\left(\mathrm{K}_{\mathrm{D}}=2.8 \times 10^{-8} \mathrm{M}\right.$; Supplemental Fig. 1; Supplemental Table 2). Proliferation and migration decreased in vSMCs treated with RS and FGF-2 (Fig. 2G, H).

Rhamnan sulfate enhances endothelial barrier function. We next examined whether RS could alter endothelial barrier function to LDL in the presence of treatments that induce inflammation or simulate the destruction of the glycocalyx. We treated endothelial cells with heparinase III, a bacterial enzyme that degrades heparan sulfate. In untreated endothelial cells this led to a drop in heparan sulfate coverage of the cells from $96 \%$ to $36 \%$ of the cells (Fig. 3A, B). With RS treatment, this heparinase-induced reduction in coverage was reduced to 59\%, indicating that RS prevented the degradation of endogenous heparan sulfate glycosaminoglycans (Fig. 3A, B). The permeability of the endothelium to LDL was lower in endothelial cells treated with RS, regardless of dose of 
heparinase applied (Fig. 3C). Using Transwell filters as the base, we also tested the effect of 30 minutes of RS incubation on the blank filter, subendothelial matrix and endothelial monolayer. Treatment with RS reduced LDL permeability by 2.7-fold for the blank filter, 8-fold for the subendothelial matrix and 4.4-fold for the endothelial monolayer (Fig. 3D). These results indicated that RS accumulates both in the matrix and on the endothelial monolayer, where it can provide enhanced barrier function. We also tested the effectiveness of RS in reducing LDL permeability in endothelial cells after combined treatment with TNF- $\alpha$ and the protein synthesis inhibitor cycloheximide (CHX). While LDL permeability increased after the TNF- $\alpha / \mathrm{CHX}$ treatment in control cells, it remained at basal levels with RS incubation (Fig. 3E). In contrast we did not observe this effect with treatment with heparin (Fig. 3E). We also examined the permeability of endothelial monolayers to VLDL and found that it was lower with RS treatment (Fig. 3F). These results suggest that RS can reduce endothelial permeability to LDL and improve overall barrier function.

\section{Rhamnan sulfate reduces TNF- $\alpha$ induced NF- $\mathrm{B}$ activation in human endothelial cells. The} $\mathrm{NF}-\kappa \mathrm{B}$ pathway is an important pathway in controlling endothelial inflammation and is implicated in atherosclerosis, lipid metabolism and control of vSMC proliferation.[40, 41] In the canonical $\mathrm{NF}-\kappa \mathrm{B}$ pathway, an NF- $\mathrm{B}$ dimer is sequestered in the cytoplasm though interaction with a member of the I $\mathrm{I} B$ family of proteins $(\mathrm{eg} . \mathrm{I} \kappa \mathrm{B} \alpha)$. Activation of a receptor leads to the recruitment of adaptor proteins followed by recruitment of the I $\mathrm{B}$ kinase complex (IKK; typically consisting of IKK $\alpha$, IKK $\beta$ and IKK $\gamma$ ), which subsequently phosphorylates I $\mathrm{KB}$ and eventually leads to its degradation. The destruction of $I \kappa B$ allows NF- $\kappa$ B dimers to translocate to the nucleus where they can control gene transcription. To examine if RS could alter signaling though the NF- $\kappa$ B pathway, we treated endothelial cells with TNF- $\alpha$ for varying times and measured the activation of NF- $\kappa \mathrm{B}$ pathway signaling intermediates using western blotting. We found that TNF- $\alpha$ induced an increase in $\mathrm{I} \kappa \mathrm{B} \alpha$ phosphorylation after 10 min of treatment, indicating activation of the NF- $\kappa \mathrm{B}$ pathway and that treatment with RS reduced this response (Fig. 4A, B). After 30 minutes of TNF- $\alpha$ treatment there was increased I $\mathrm{B} \alpha \alpha$ degradation and this was not affected by RS but basal levels

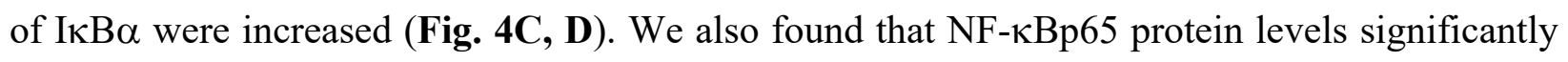
decreased by RS treatment in the nuclear fraction and increased in the cytoplasm fraction after 30 


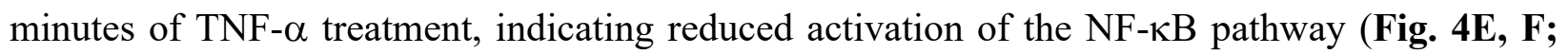
Supplemental Fig. 2). In addition, phosphorylation of IKK, the complex responsible for the phosphorylation of $\mathrm{I} \kappa \mathrm{B} \alpha$, was also significantly reduced by RS treatment (Fig. 4G, H). Together, these findings indicate that RS affects multiple steps in the canonical pathway of NF- $\kappa \mathrm{B}$ activation by TNF- $\alpha$. To further confirm these findings, we measured NF- $\kappa$ Bp65 activity directly using a TransAM assay and found that activity was reduced in the nuclear extracts of TNF- $\alpha$ treated endothelial cells (Fig. 4I). As we had observed nuclear localization of RS in our trafficking studies, we hypothesized that RS may bind directly to some of the components of the NF- $\mathrm{B}$ pathway. Using surface plasmon resonance, we found that RS binds with high affinity to NF- $\kappa$ Bp50 $\left(\mathrm{K}_{\mathrm{D}}=\right.$ $\left.1.1 \times 10^{-7} \mathrm{M}\right)$ and NF- $\kappa B p 65\left(\mathrm{~K}_{\mathrm{D}}=2.3 \times 10^{-8} \mathrm{M}\right.$; Fig. 4J, K). The dissociation constant for the proteins for binding to RS was comparable to binding with heparin (Supplemental Table 2).

Rhamnan sulfate has oral bioavailability and is found in vascular tissues after oral administration. Prior to conducting an in vivo experiment with oral RS, we studied the pharmacokinetics of the drug to calculate the clearance rate and uptake by aorta, heart, blood and liver. We introduced RS in mice though oral gavage and measured the concentration in tissues over 24 hours. In the abdominal aorta, RS concentration started decreasing after 4 hours but continued to rise steadily for 24 hours in the thoracic aorta (Supplemental Fig. 3A). In the heart and total blood plasma, RS concentrations increased up to 4 and 12 hours respectively before being cleared (Supplemental Fig. 3B). In the liver, there was an initial influx of RS at 4 hours and then a gradual increase in concentration after 12 hours (Supplemental Fig. 3B). We also injected FITC labeled RS into the blood directly and examined its clearance. We calculated the half-life of RS to be approximately 21.1 minutes in the blood following intravenous injection (Supplemental Fig. 3C).

\section{Orally administered rhamnan sulfate decreases plaque deposition in $\mathrm{ApoE}^{-/-}$mice on a high}

fat diet. To test the effect of RS on the progression of atherosclerosis, ApoE ${ }^{-/-}$mice were fed a high fat diet or a high fat diet supplemented with RS for 13 weeks (Supplemental Fig. 4). Blood cholesterol levels were decreased significantly in female $\mathrm{ApoE}^{-/-}$mice treated with $\mathrm{RS}$ but not in male mice (Fig. 4A). There was no change in plasma triglyceride levels in both male and female mice (Supplemental Fig. 5). In en face preparations of the aorta, lipid deposition was decreased 
by $45.2 \%$ in female and $36.4 \%$ in male mice whole aortas with RS treatment in comparison to the $\mathrm{ApoE}^{-/-}$HFD group (Fig. 5B, C). In the aortic arch, there was also significant decrease in lipid deposition in the male and female $\mathrm{ApoE}^{-/-}$mice with RS treatment. Stenosis decreased in female mice only (Fig. 5D, E). In the thoracic aorta, there was a reduction in lipid deposition, lesion area and stenosis for female mice treated with RS but not for male mice (Fig. 5F, G).

Oral rhamnan sulfate does not affect body weight or adipose tissue deposition in $\mathrm{ApoE}^{-/-}$ mice. There was no difference in the weight of the mice between the RS treated and untreated mice for both male and female groups (Supplemental Fig. 6A, B). There was also no significant difference in the ratio of liver, inguinal white adipose tissue (iWAT) and gonadal white adipose tissue (gWAT) to total body weight in female mice (Supplemental Fig. 6C). Also, characterization of the iWAT and gWAT showed no change in size of adipocytes in treated female mice (Supplemental Fig. 7A). In male mice, the ratio of gWAT to total body weight increased in mice treated with RS (Supplemental Fig. 7D). The size of adipocytes remained the same in both iWAT and gWAT in the HFD and HFD+RS treated groups (Supplemental Fig. 7B).

\section{Rhamnan sulfate treatment reduces high fat diet induced increases in blood velocity in ApoE ${ }^{-}$}

I- mice. To monitor plaque development over the course of the experiment, we measured blood velocity in the aorta and left common carotid arteries of $\mathrm{ApoE}^{-/-}$mice. Peak systolic velocity (PSV), end diastolic velocity (EDV) and mean velocity (MV) were calculated in the ascending and descending aorta, aortic arch and, carotid artery. In female mice, PSV, EDV and, MV decreased with RS treatment in the ascending aorta (Supplemental Fig. 8, Supplemental Fig. 9A). In the aortic arch for female mice, there was no change in blood flow velocities with RS treatment but there was a significant decrease in flow velocities in the descending aorta for the PSV and EDV with RS treatment (Supplemental Fig. 8). All flow velocities decreased in the carotid artery with RS treatment as well for female mice (Supplemental Fig. 8; Supplemental Fig. 10A). In male mice, there was no change in all three velocities in the ascending aorta and only EDV decreased in the aortic arch (Supplemental Fig. 8; Supplemental Fig. 9B). In the descending aorta, PSV, EDV and, MV all decreased with RS treatment while there no change in the velocities in the carotid artery (Supplemental Fig. 8; Supplemental Fig. 10B). In addition, we found that the elasticity, 
measured by circumferential strain, of the aorta during the cardiac cycle was higher in female mice treated with RS (Supplemental Fig. 11).

Rhamnan sulfate reduces vascular inflammation in female mice but not male mice. To quantify the efficacy of oral RS in reducing vascular inflammation, we examined the presence of macrophages and activation of the NF- $\mathrm{B}$ pathway in the ApoE $\mathrm{E}^{-/-}$mice treated with HFD or HFD with RS supplementation. There was a significant decrease in macrophages (F4/80 positive cells) in histological sections from the aortic root in female mice treated with RS in comparison to the HFD group but there was no change in male mice (Fig. 6A, B). Also, I $\kappa \mathrm{B} \alpha$, an inhibitor of NF$\kappa \mathrm{B}$, was significantly upregulated in female mice (Fig. 6C, D). Phosphorylation of the p65 subunit of NF- $\kappa \mathrm{B}$ was also reduced in female $\mathrm{ApoE}^{-/-}$mice on a HFD treated with RS (Fig. 6E; Supplemental Fig. 13). Phosphorylation of $\mathrm{p} 65, \mathrm{I} \kappa \mathrm{B} \alpha$ and $\mathrm{F} 4 / 80$ were not affected by $\mathrm{RS}$ treatment in male mice (Fig. 6B, D, E).

Treatment with RS reduces plaque angiogenesis and enhances endothelial eNOS production in $\mathrm{ApoE}^{-/-}$mice on a high fat diet. During atherosclerotic inflammation, endothelial permeability is increased by PECAM-1 upregulation as it promotes leukocyte transmigration and integrin activation. In both female and male $\mathrm{ApoE}^{-/-}$mice, PECAM-1 was decreased with RS treatment (Fig. 6F; Supplemental Fig. 12). Impaired eNOS levels lead to atherogenesis though increased nitric oxide breakdown and superoxide production.[42] In female mice treated with RS, there was higher eNOS production in the aortic arch (Fig. 6G; Supplemental Fig. 12). There was increased area of $\alpha$-SMA staining in the aortic arch of female ApoE ${ }^{-/-}$mice treated with RS, reflecting the reduction in plaque size (Fig. 6H; Supplemental Fig. 12). In male mice, eNOS and $\alpha$-SMA were not affected by RS treatment (Fig. 6G, H). 


\section{Discussion}

Atherosclerosis is a chronic disease characterized by inflammation, lipid accumulation and the progressive development of plaques.[1],[2] Lipid lowering therapies including statins have provided significant reductions in the risk of fatal coronary heart disease and non-fatal myocardial infarction. However, in spite of these advancements, atherosclerotic disease continues to be a pervasive clinical problem.[43] Atherosclerosis slowly progresses for life, placing more strict requirements on pharmaceutical products to treat vascular disease in comparison to many other diseases. Compounds for treating atherosclerosis will need to be taken orally by patients on a daily basis for decades, requiring long-term safety and representing a major investment by healthcare systems to provide for patients. Our studies demonstrate that rhamnan sulfate has potent antiinflammatory properties, reduces vSMC proliferation and reduces atherosclerosis in a hyperlipidemic mouse model. As rhamnan sulfate is relatively inexpensive and has been consumed by millions of people as part of their diet, it would present an easily implementable adjuvant therapy to lipid lowering drugs and other treatments for atherosclerotic disease if it were effective in human patients.

Our studies indicate that rhamnan sulfate has atheroprotective effects though multiple modes of action. It reduces migration of vascular cells and binds to pro-growth and inflammatory growth factors with an affinity similar to that of heparin, suppressing the growth of vSMCs. Our studies suggest that this effect could proceed through binding of growth factors including FGF-2 and PDGF-BB. However, RS also inhibits migration in the absence of stimulation with these factors suggesting it may also act by directly altering cellular adhesion/migration mechanisms. The uptake of RS was reduced in both endothelial and vascular smooth muscle cells with rottlerin treatment. This indicates that a major mechanism of entry into the cells is macropinocytosis. In vSMCs, mitomycin treatment also reduced nuclear levels of RS, implying that RS may enter the nucleus during mitosis. This effect may be more pronounced in vSMCs due to their higher proliferation rate.

Our work indicates that rhamnan sulfate accumulates in vascular cells over the course of several days and is also deposited in the extracellular matrix. Interestingly, rhamnan sulfate appears to be able to access and bind to nuclear protein during cell division. This finding suggests a novel mechanism of action for RS, in which it accumulates in the cytoplasm of the cells followed by binding to nuclear proteins, including $\mathrm{NF}-\kappa \mathrm{B}$, during cell division. The polyanionic structure 
of rhamnan sulfate may mimic that of DNA, allowing it to competitively bind to regions of proteins that bind to DNA. In comparison, heparin can facilitate the nuclear entry of growth factors but heparin and its anti-proliferative derivatives do not enter the nucleus of vSMCs.[44] Prior studies have also suggested that the cellular localization of low molecular weight heparin is dependent on sulfation; however, none of the modified forms are found in the nucleus.[45] Thus, rhamnan sulfate is likely not simply acting as a heparin analogue in this activity.

A striking feature of our findings is the differences in response between male and female animals treated with rhamnan sulfate. In the blood vessels in mice treated with rhamnan sulfate, at the aortic root there was a more pronounced reduction in lipid area for male mice, but the overall lesion and stenotic response was only significantly lower in females. In the thoracic aorta, only female mice had a reduction in plaque size and stenosis. We also observed a stronger cholesterollowering effect of rhamnan sulfate in female mice compared to male mice. Lipid lowering effects have been observed for marine polysaccharides including fucoidan, ulvan, and laminarin sulfate.[46-48] In comparison to these, rhamnan sulfate did not produce as dramatic reductions in lipids. The anti-inflammatory properties of rhamnan sulfate appeared to be stronger in female mice as well, including significant lowering of plaque inflammation and lipids with rhamnan sulfate treatment.

Overall, our studies demonstrate that rhamnan sulfate can provide significant benefits for inhibiting the development of atherosclerosis and acts though multiple mechanisms including the reduction of inflammation, inhibition of vascular cell proliferation and enhanced endothelial barrier function. Due to the low cost and ease of availability, RS may have high potential as an easily implementable adjunct therapy for atherosclerosis. Our studies used a highly purified form of rhamnan sulfate, which may allow it to have increased binding capacity and activity in comparison to less pure forms. Further studies would be needed to determine if less purified forms of the compound have similar activity and if particular subfractions of RS can be linked to specific mechanistic activities.

Acknowledgements. The authors gratefully acknowledge funding though the American Heart Association (17IRG33410888), the DOD CDMRP (W81XWH-16-1-0580; W81XWH-16-1-0582) and the National Institutes of Health (1R21EB023551-01; 1R21EB024147-01A1; 
1R01HL141761-01) to ABB. This work was funded by National Institutes of Health Grants DK111958, CA231074, NS088496 and AG062344 to RJL.

Disclosures. None. 


\section{Figure Legends}

Figure 1. Vascular cells internalize RS primarily through macropinocytosis. (A) Vascular smooth muscle cells were incubated with FITC-labeled RS $(1000 \mu \mathrm{g} / \mathrm{mL})$ with or without treatment with mitomycin for the indicated times. Scale bar $=20 \mu \mathrm{m}$. (B) Endothelial cells were incubated with FITC-labeled RS $(1000 \mu \mathrm{g} / \mathrm{mL})$ with or without treatment with rottlerin. Scale bar $=20 \mu \mathrm{m}$. C) Uptake of RS in (s treated with mitomycin decreased over three days. ${ }^{*} p<0.05$ versus control day 1. ${ }^{\dagger} p<0.05$ versus treatment group on day $1 .{ }^{\ddagger} p<0.05$ versus control for each time point. D) In endothelial cells treated with mitomycin, uptake of RS appeared to increase over three days. * $p<$ 0.05 versus control day $1 .{ }^{\dagger} p<0.05$ versus treatment group on day $1 .{ }^{\ddagger} p<0.05$ versus control for each time point. Quantification of total and nuclear uptake of RS in (E) vSMCs or (F) endothelial cells treated with nystatin, an inhibitor of caveolin-mediated endocytosis. Quantification of total and nuclear uptake of RS in $(\mathrm{G})$ vSMCs or $(\mathrm{H})$ endothelial cells treated with pitstop 2, an inhibitor of clathrin-mediated endocytosis. Quantification of total and nuclear uptake of RS in (I) vSMCs or (J) endothelial cells treated with rottlerin, an inhibitor of macropinocytosis. ${ }^{*} p<0.05$ versus control day $1 .{ }^{\dagger} p<0.05$ versus treatment group on day $1 .{ }^{\ddagger} p<0.05$ versus control for each time point. (F) Images of endothelial cells that were incubated with FITC-labeled RS $(1000 \mu \mathrm{g} / \mathrm{mL})$ with or without treatment with rottlerin for the indicated times. Scale bar $=20 \mu \mathrm{m}$. Quantification of total and nuclear uptake of RS in endothelial cells treated with (B) mitomycin, (C) nystatin, (D) pitstop, and (E) rottlerin. ${ }^{*} p<0.05$ versus control day $1 .{ }^{\dagger} p<0.05$ versus treatment group on day 1. ${ }^{\ddagger} p<0.05$ versus control for each time point ( $\mathrm{n}=10$ for all groups).

Figure 2. Rhamnan sulfate decreases proliferation and migration of vascular cells. (A) Endothelial cells were treated with FGF-2 and RS in ORIS assay. Scale bar $=100 \mu \mathrm{m}$. (B) Migration of endothelial cells treated with FGF-2 was reduced by RS $(\mathrm{n}=10) .{ }^{*} p<0.05$ versus $0 \mu \mathrm{g} / \mathrm{mL} \mathrm{RS}$, ${ }^{\dagger} p<0.05$ versus $0 \mu \mathrm{g} / \mathrm{mL} \mathrm{RS}+\mathrm{FGF}-2,{ }^{\ddagger} p<0.05$ versus respective control. (C) Proliferation of endothelial cells treated with FGF-2 and RS decreased after 72 hours $(\mathrm{n}=16) .{ }^{*} p<0.05$ versus 0 $\mu \mathrm{g} / \mathrm{mL} \mathrm{RS},{ }^{\dagger} p<0.05$ versus $0 \mu \mathrm{g} / \mathrm{mL}$ RS $+\mathrm{FGF}-2,{ }^{\ddagger} p<0.05$ versus respective control. (D) Vascular smooth muscle cells expressing GFP were treated with PDGF-BB and 0, 100 and $1000 \mu \mathrm{g} / \mathrm{mL}$ of RS in ORIS assay. Scale bar $=100 \mu \mathrm{m}$. (E) Migration of vSMCs treated with PDGF-BB was decreased by $\mathrm{RS}(\mathrm{n}=10) .{ }^{*} p<0.05$ versus $0 \mu \mathrm{g} / \mathrm{mL} \mathrm{RS},{ }^{\dagger} p<0.05$ versus $0 \mu \mathrm{g} / \mathrm{mL} \mathrm{RS}+\mathrm{PDGF}-$ BB. (F) Vascular smooth muscle cells treated with PDGF-BB and RS proliferated less after $72 \mathrm{~h}$ 
(n=16). ${ }^{*} p<0.05$ versus $0 \mu \mathrm{g} / \mathrm{mL} \mathrm{RS},{ }^{\dagger} p<0.05$ versus $0 \mu \mathrm{g} / \mathrm{mL}$ RS+PDGF-BB, ${ }^{\ddagger} p<0.05$ versus respective control. (G) Migration of cells vSMCs treated with FGF-2 and RS increased after 72 hours of treatment $(\mathrm{n}=10) .{ }^{*} p<0.05$ versus $0 \mu \mathrm{g} / \mathrm{mL} \mathrm{RS},{ }^{\dagger} p<0.05$ versus $0 \mu \mathrm{g} / \mathrm{mL} \mathrm{RS}+\mathrm{FGF}-2$, ${ }^{\ddagger} p<0.05$ versus respective control. (H) Proliferation of vSMCs induced by FGF-2, was also reduced after $72 \mathrm{~h}$ with $\mathrm{RS}$ treatment $(\mathrm{n}=16)$. ${ }^{*} p<0.05$ versus $0 \mu \mathrm{g} / \mathrm{mL} \mathrm{RS},{ }^{\dagger} p<0.05$ versus 0 $\mu \mathrm{g} / \mathrm{mL} \mathrm{RS}+\mathrm{FGF}-2,{ }^{\ddagger} p<0.05$ versus respective control.

Figure 3. Rhamnan sulfate reduces LDL permeability in endothelial cells. (A) Endothelial cells were treated with RS $(25 \mu \mathrm{g} / \mathrm{mL})$ and heparinase III $(135 \mathrm{mU} / \mathrm{mL})$ and immunostained for heparan sulfate. Scale bar $=20 \mu \mathrm{m}$. (B) Heparan sulfate coverage, reduced by heparinase III, was increased in ECs treated with $\mathrm{RS}(\mathrm{n}=8) .{ }^{*} p<0.05$ versus $0 \mathrm{mU} / \mathrm{mL}$ heparinase III, ${ }^{\dagger} p<0.05$ versus 0 $\mathrm{mU} / \mathrm{mL}$ heparinase III $+\mathrm{RS},{ }^{\ddagger} p<0.05$ versus $135 \mathrm{mU} / \mathrm{mL}$ heparinase III. (C) Permeability of LDL was decreased in ECs treated with RS regardless of heparinase III dose $(\mathrm{n}=4-8) .{ }^{*} p<0.05$ versus respective control. (D) Permeability of LDL was reduced in blank Transwell filters and those with subendothelial matrix and endothelial cell monolayer with $\mathrm{RS}$ incubation $(\mathrm{n}=4) .{ }^{*} p<0.05$ versus respective control. (E) Permeability of LDL was lower with RS treatment despite addition of TNF$\alpha$ and cycloheximide. Heparin treatment produced no change in the same conditions $(\mathrm{n}=4-19) .{ }^{*} p$ $<0.05$ versus control, ${ }^{\dagger} p<0.05$ versus control+TNF- $\alpha /$ chx. (F) Permeability of VLDL also decreased by $\mathrm{RS}$ treatment $(\mathrm{n}=8) .{ }^{*} p<0.05$ versus control.

Figure 4. Rhamnan sulfate reduces NF- $\kappa \mathrm{B}$ activation in endothelial cells. (A) Endothelial cells were treated with TNF- $\alpha(10 \mathrm{ng} / \mathrm{mL})$ for 10 minutes to cause I $\mathrm{B} \alpha$ phosphorylation. (B) Western blot analysis showed decrease in $\mathrm{p}-\mathrm{I} \kappa \mathrm{B} \alpha$ in total protein of cells pre-treated with $\mathrm{RS}(\mathrm{n}=2-15) .{ }^{*} p$ $<0.05$ versus control, ${ }^{\dagger} p<0.05$ versus TNF- $\alpha$. (C) Endothelial cells were treated with TNF- $\alpha$ (10 $\mathrm{ng} / \mathrm{mL}$ ) for 30 minutes to cause degradation of I $\mathrm{B} \alpha$ phosphorylation. (D) Western blotting showed increase in I $\kappa \mathrm{B} \alpha$ in the absence of TNF- $\alpha$ with RS treatment $(\mathrm{n}=7-11)$. ${ }^{*} p<0.05$ versus control, ${ }^{\dagger} p<0.05$ versus TNF- $\alpha$. (E) Endothelial cells were treated with TNF- $\alpha(10 \mathrm{ng} / \mathrm{mL})$ for 30 minutes to cause NF- $\kappa \mathrm{B}$ translocation into the nucleus. (F) Western blotting showed decrease in p65 subunit of NF- $\kappa$ B in nuclear fraction of cells pre-treated with RS $(\mathrm{n}=6) .{ }^{*} p<0.05$ versus control, ${ }^{\dagger} p<0.05$ versus TNF- $\alpha$. (G) Endothelial cells were treated with TNF- $\alpha(10 \mathrm{ng} / \mathrm{mL})$ for 10 minutes to cause activation of the IKK complexes. $(\mathrm{H})$ Western blotting showed decrease in $\mathrm{p}$-IKK $\alpha / \beta$ but 
no change in IKK $\alpha$ and IKK $\beta$ in total protein of cells pre-treated with RS $(\mathrm{n}=2-11) .{ }^{*} p<0.05$ versus control, ${ }^{\dagger} p<0.05$ versus TNF- $\alpha$. (I) TransAM assay showed reduced NF- $\kappa \mathrm{B} / \mathrm{p} 65$ activity after treatment with $100 \mu \mathrm{g} / \mathrm{mL}$ RS dose $(\mathrm{n}=8) .{ }^{*} p<0.05$ versus control, ${ }^{\dagger} p<0.05$ versus TNF-

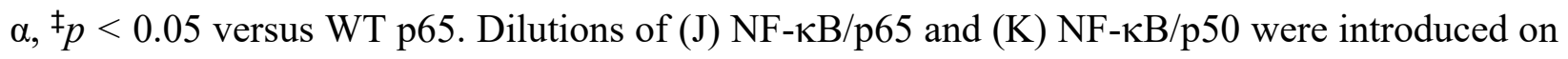
a sensor surface with RS and dissociation with HBS-EP buffer measured for three minutes. After three minutes, the surface was regenerated with $2 \mathrm{M} \mathrm{NaCl}$ and total response monitored in sensorgram $(n=5)$.

Figure 5. Rhamnan sulfate reduces atherosclerotic plaque area and plasma cholesterol in $\mathrm{ApoE}^{-/-}$ mice. (A) Plasma cholesterol was lower by $22.5 \%$ in female $\mathrm{ApoE}^{-/-}$mice fed HFD and RS ( $\mathrm{n}=$ 10). ${ }^{*} p<0.05$ versus control, ${ }^{\dagger} p<0.05$ versus ApoE ${ }^{-/-}$HFD. (B) Lipid deposition in the whole aorta was reduced by $45.2 \%$ in female and $36.4 \%$ in male $\mathrm{ApoE}^{-/-}$mice fed HFD and RS $(\mathrm{n}=3)$. ${ }^{*} p<0.05$ versus control, ${ }^{\dagger} p<0.05$ versus ApoE ${ }^{-/-}$HFD. (C) En face staining of aortas of female and male mice for C57BL/6 mice fed a standard diet, ApoE ${ }^{-/-}$mice fed a HFD and $\mathrm{ApoE}^{-/-}$mice fed a HFD with RS. Scale bar $=100 \mu \mathrm{m}$. (D) Aortic arch sections of female (shown) and male mice in the three groups were stained with Oil Red-O. Scale bar $=100 \mu \mathrm{m}$. (E) Lipid deposition, lesion area and stenosis were reduced in aortic arches of female ApoE ${ }^{-/-}$mice fed HFD with RS. Lipid deposition only was reduced in aortic arches of male $\mathrm{ApoE}^{-/-}$mice fed HFD with RS $(n=7)$. ${ }^{*} p<0.05$ versus control, ${ }^{\dagger} p<0.05$ versus ApoE ${ }^{-/}$HFD. (F) Histological sections of the thoracic aorta of female (shown) and male mice in the three groups were stained with Oil Red-O and hematoxylin and eosin. Scale bar $=100 \mu \mathrm{m}$. (G) Lipid deposition, lesion area and stenosis were reduced in thoracic aortas of female $\mathrm{ApoE}^{-/-}$mice fed a HFD with $\mathrm{RS}(\mathrm{n}=7)$. ${ }^{*} p<0.05$ versus control, ${ }^{\dagger} p<0.05$ versus ApoE ${ }^{-/-}$HFD.

Figure 6. Attenuation of inflammatory markers by RS in the aortic arch. (A) Aortic arch histology sections of female (shown) and male mice in the three groups were stained for F4/80. Scale bar $=$ $100 \mu \mathrm{m}$. (B) In female mice treated with RS, there was a reduction of $\mathrm{F} 4 / 80$ positive staining $(\mathrm{n}=$ 7). ${ }^{*} p<0.05$ versus control STD, ${ }^{\dagger} p<0.05$ versus ApoE ${ }^{-/-}$HFD. (C) Aortic arch sections were also stained for $\mathrm{I} \kappa \mathrm{B} \alpha$. Scale bar $=100 \mu \mathrm{m}$. (D) There was an increase in $\mathrm{I} \kappa \mathrm{B} \alpha$ positive staining in female $\mathrm{ApoE}^{-/-}$mice fed HFD with RS $(\mathrm{n}=7) .{ }^{*} p<0.05$ versus control $\mathrm{STD},{ }^{\dagger} p<0.05$ versus

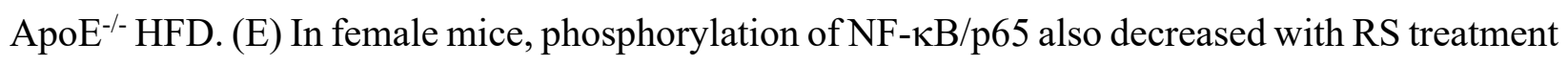


$(\mathrm{n}=7) .{ }^{*} p<0.05$ versus control STD,${ }^{\dagger} p<0.05$ versus ApoE ${ }^{-/-}$HFD. (F) Positive staining for PECAM-1 was lower in female and male mice treated with $\mathrm{RS}(\mathrm{n}=7) .{ }^{*} p<0.05$ versus control $\mathrm{STD},{ }^{\dagger} p<0.05$ versus ApoE ${ }^{-/-}$HFD. Finally, in female mice, $(\mathrm{G})$ eNOS and $(\mathrm{H}) \alpha-\mathrm{SMA}$ staining were increased with $\mathrm{RS}$ treatment $(\mathrm{n}=7)$. ${ }^{*} p<0.05$ versus control $\mathrm{STD},{ }^{\dagger} p<0.05$ versus $\mathrm{ApoE}^{-/-}$ HFD. 


\section{Figure 1}
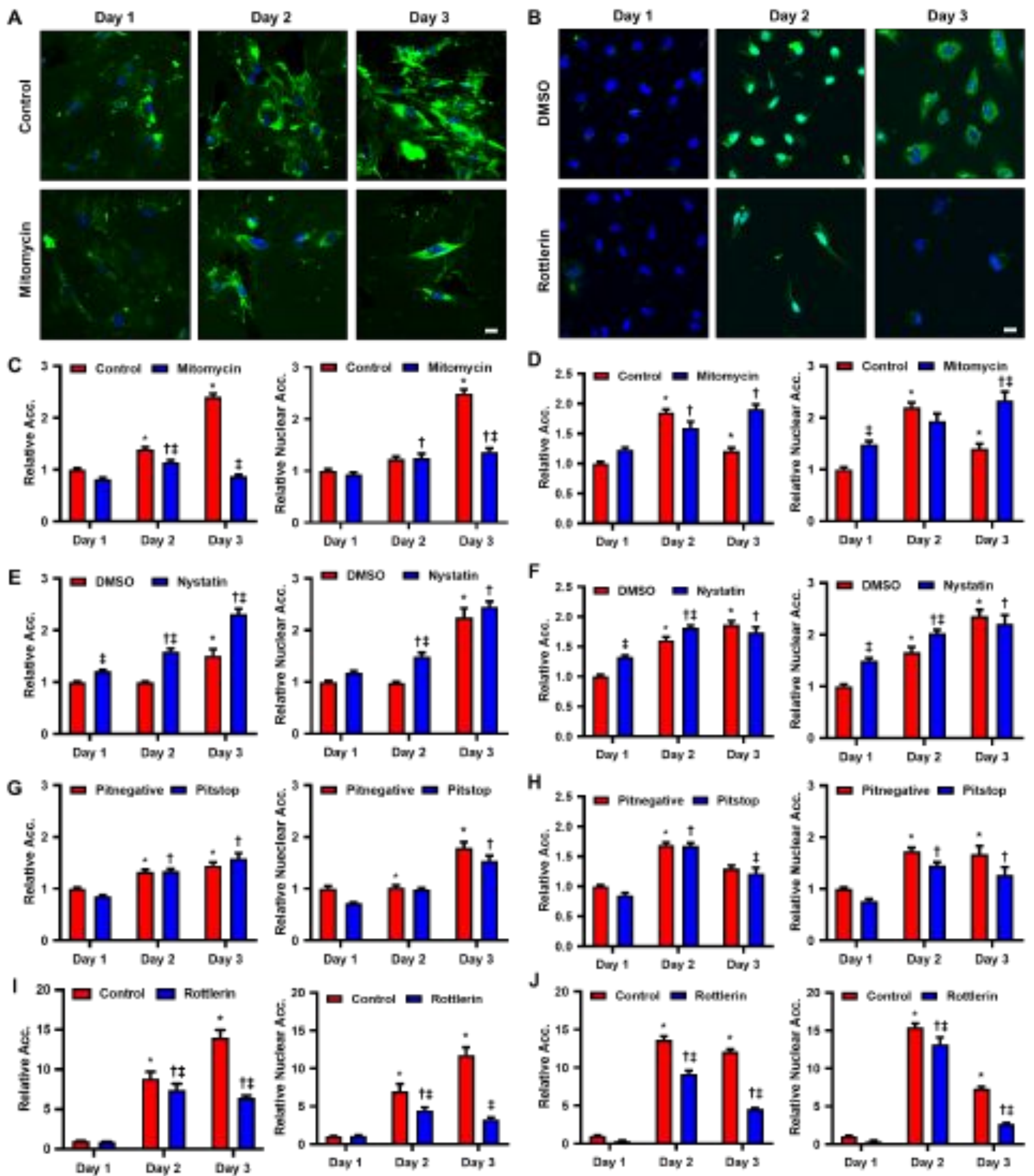
Figure 2

A

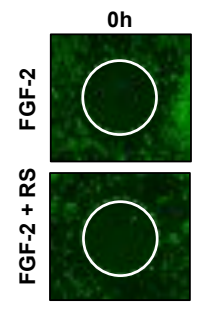

D
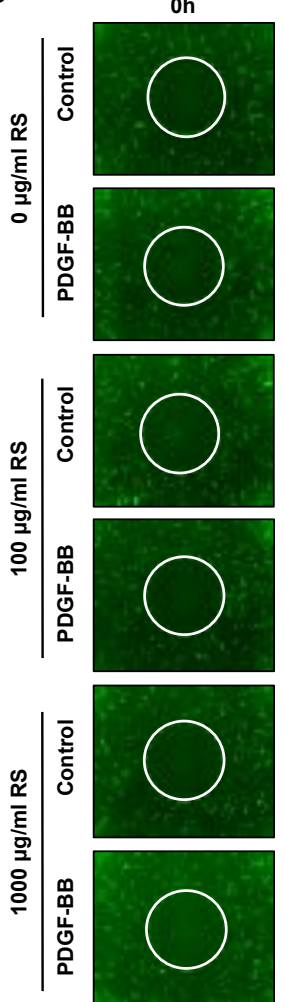
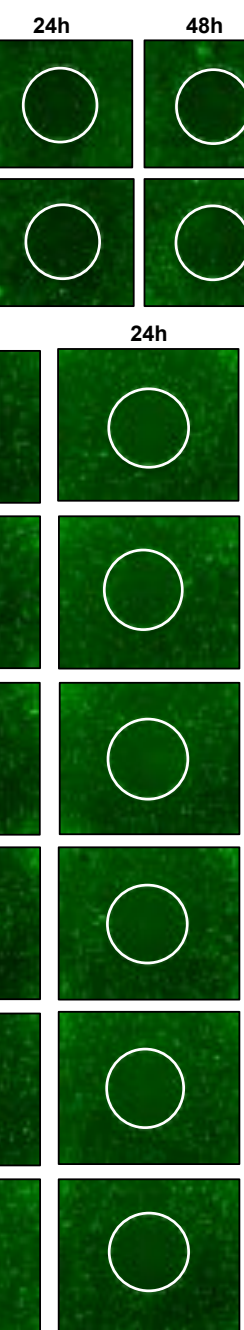

$24 \mathrm{~h}$
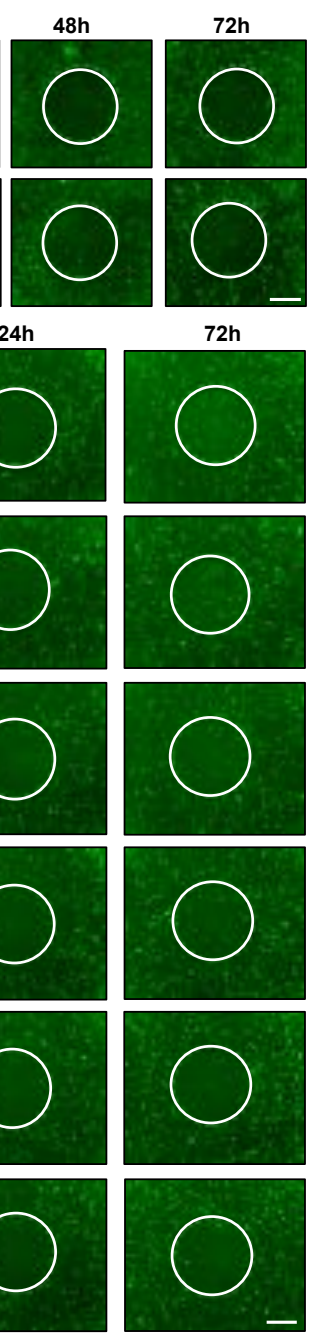

B
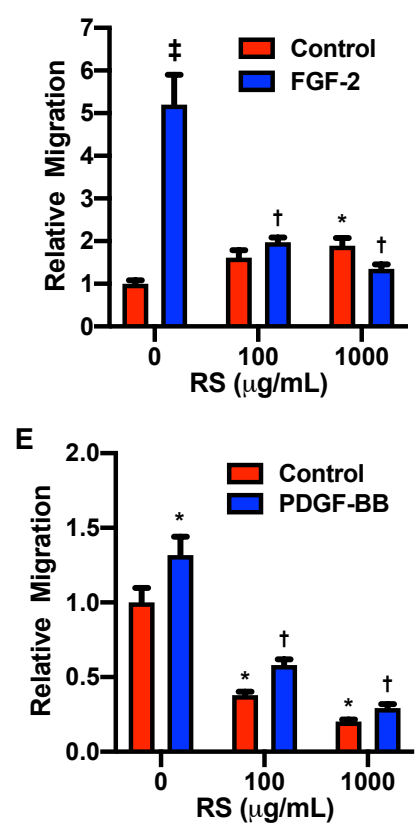

G

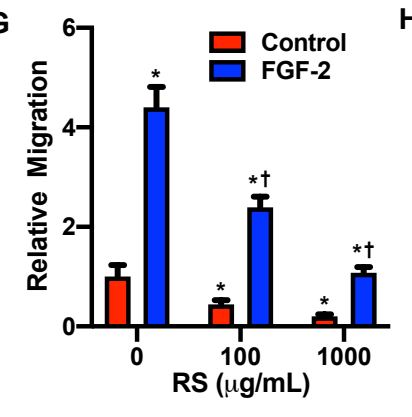

C

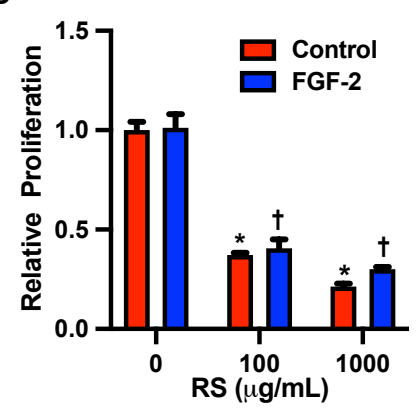

F
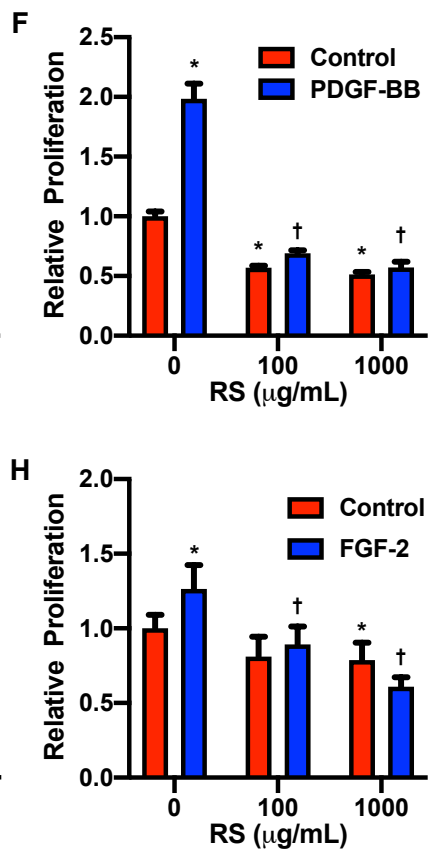
Figure 3
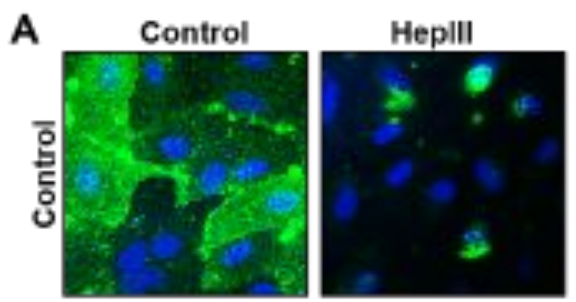

B

C
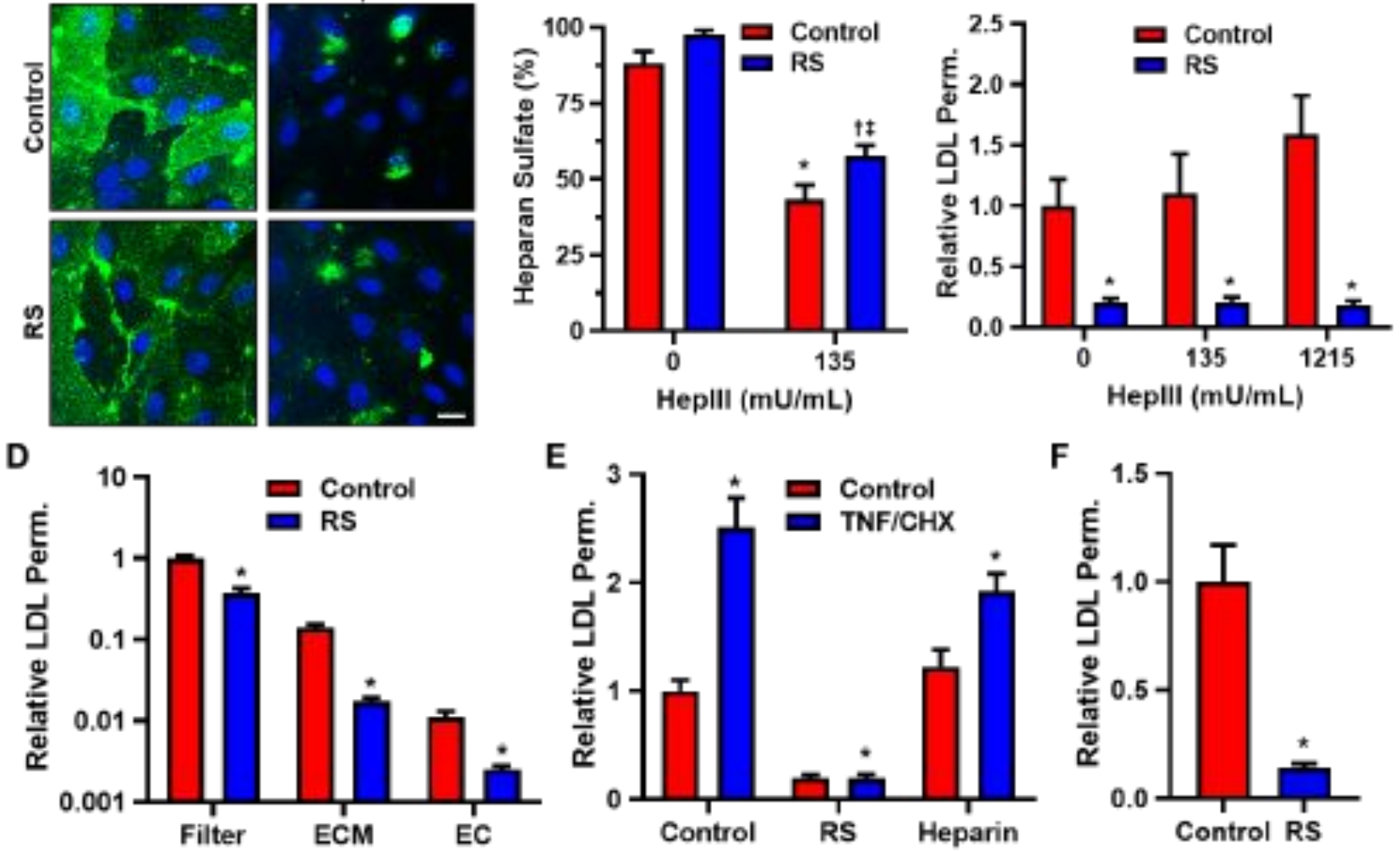


\section{Figure 4}
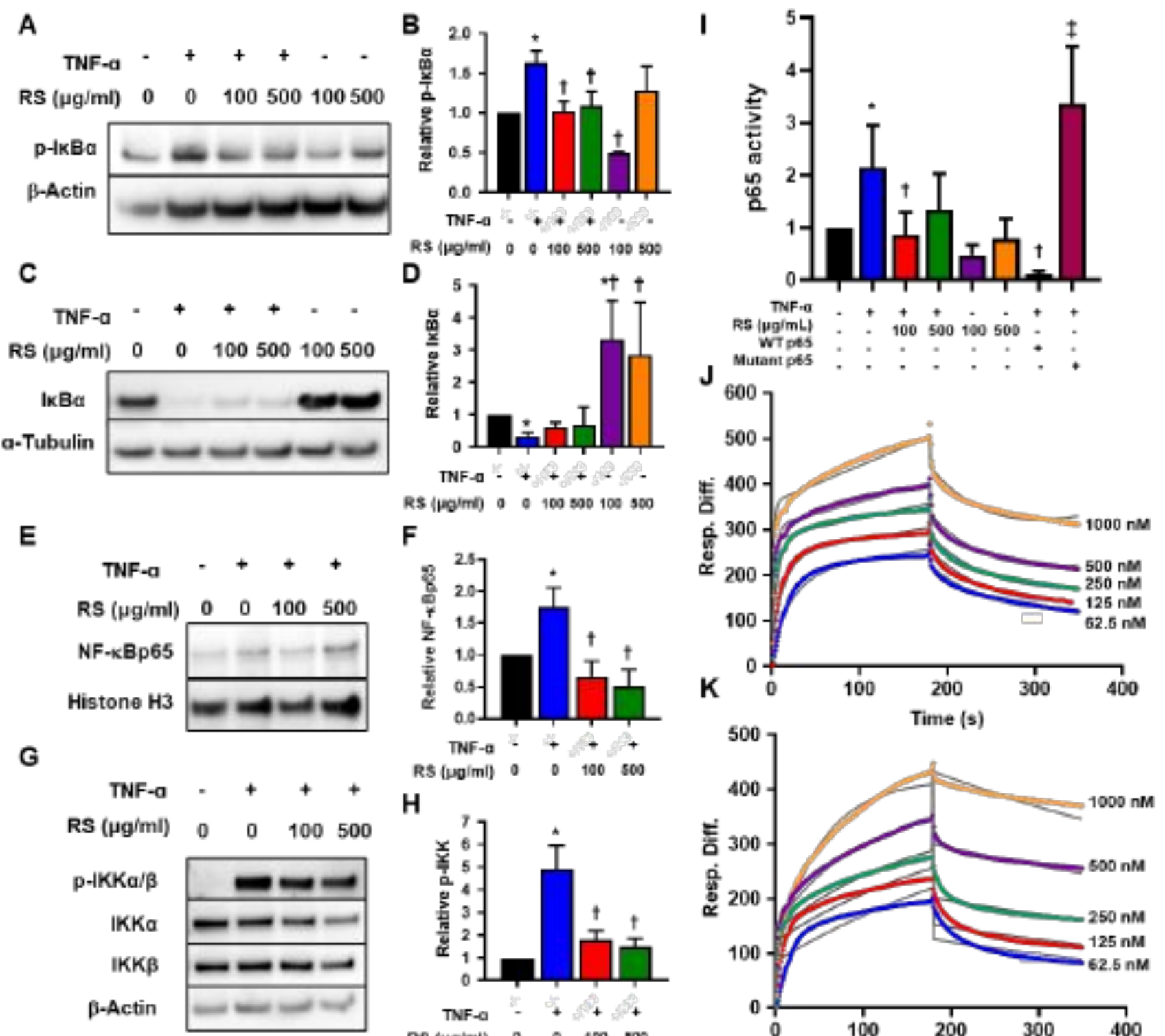

E

F
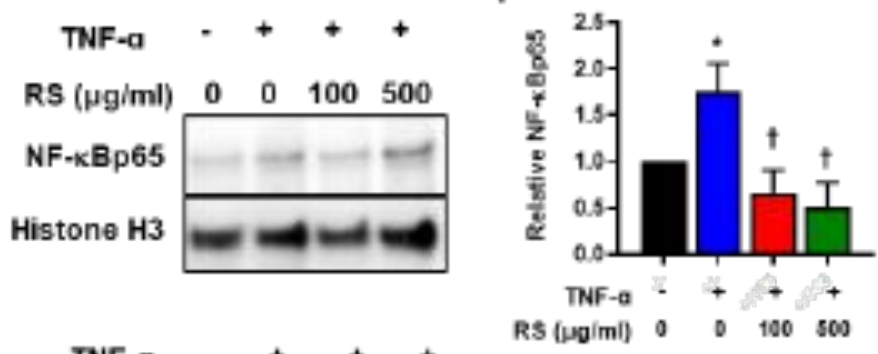

H
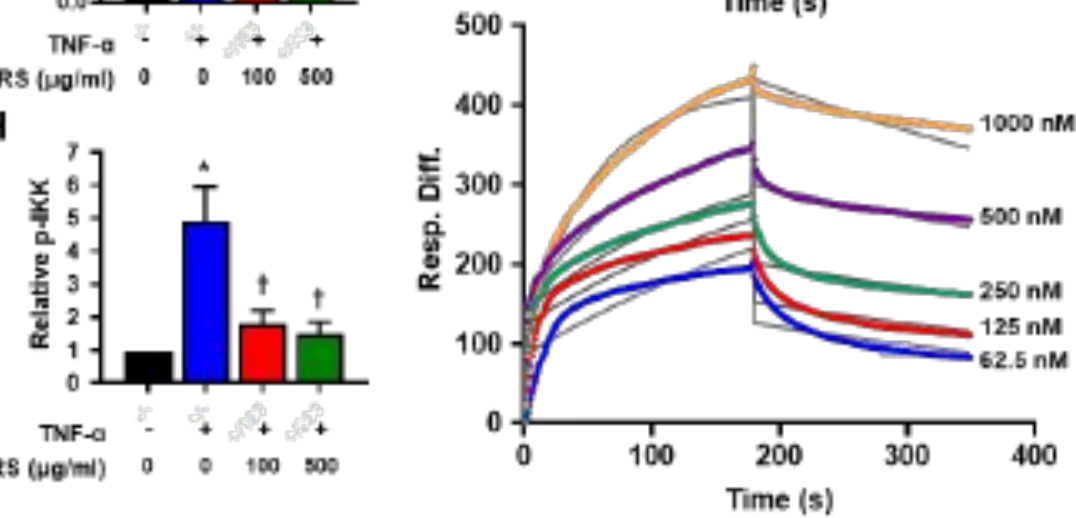
Figure 5

A

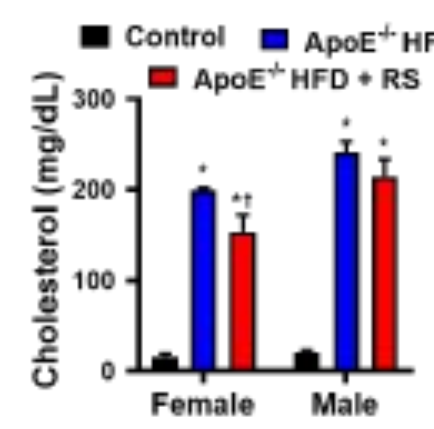

B

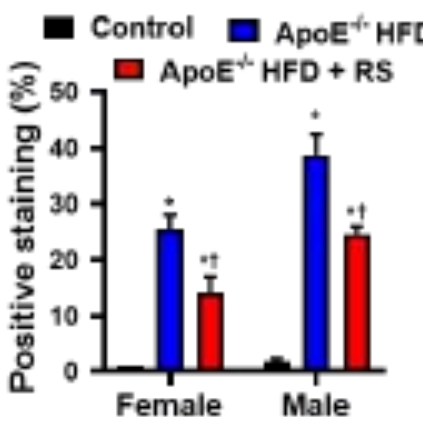

C

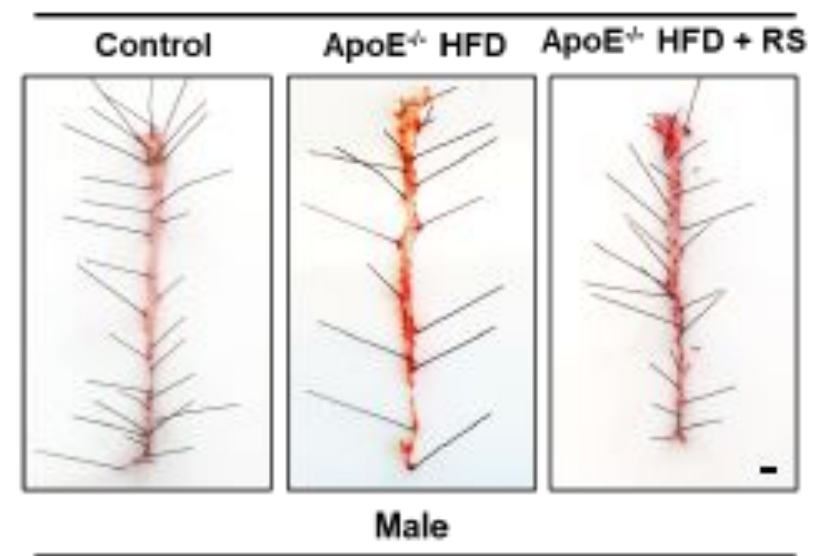

Female

ApoE $^{\star}$ HFD

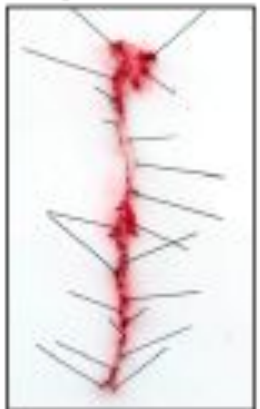

ApoE* HFD + RS

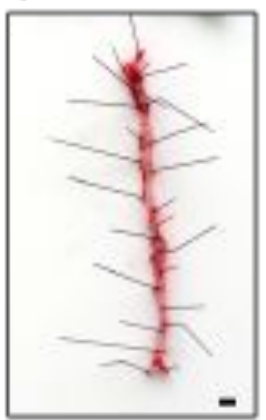

D

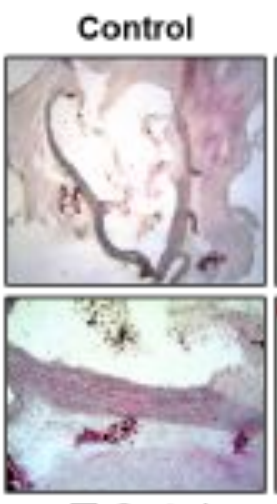

ApoE* HFD

ApoE* HFD + RS

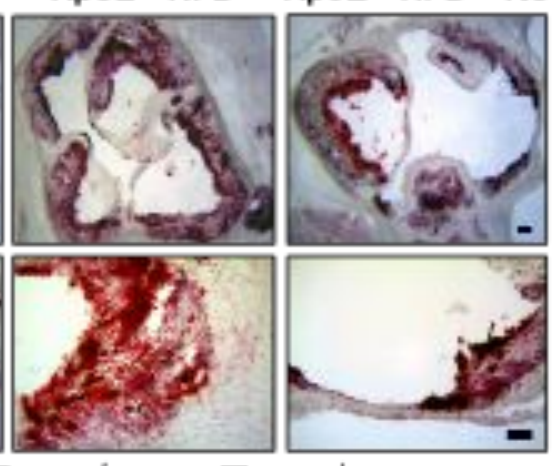

E
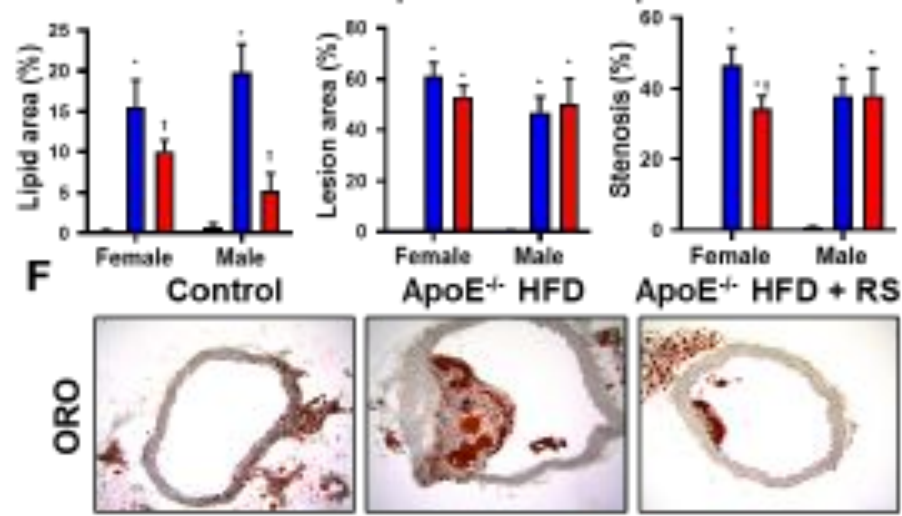

$A p o E+H F D+R S$
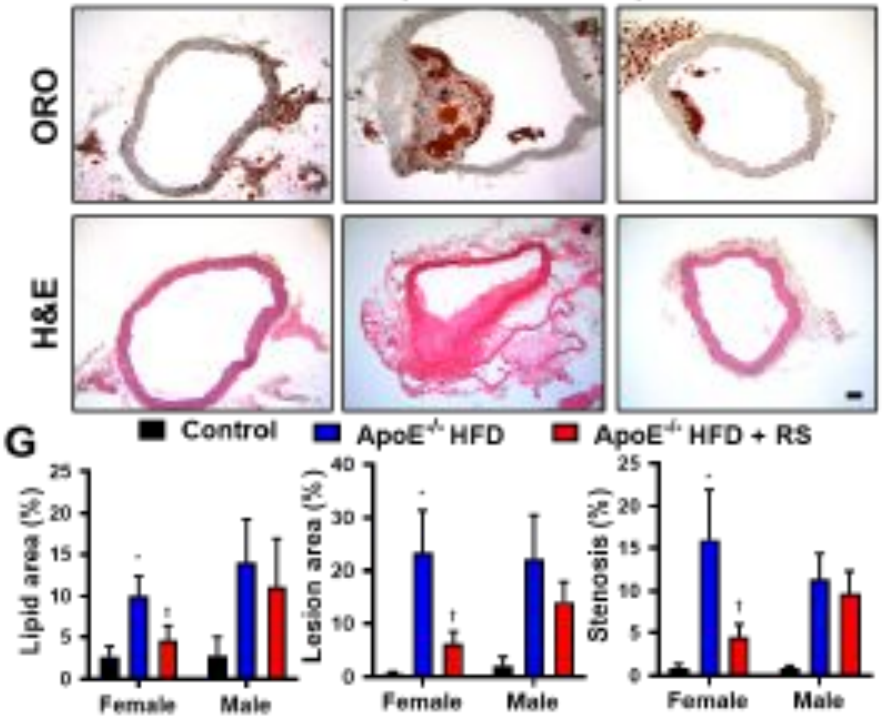
Figure 6

A

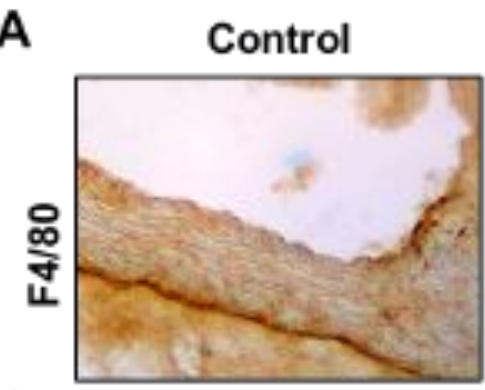

C

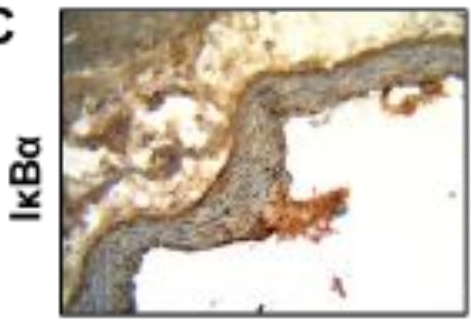

E

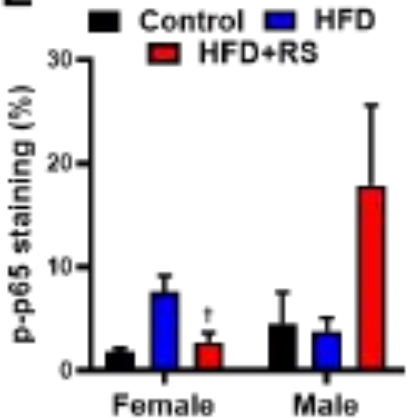

$\mathbf{F}$

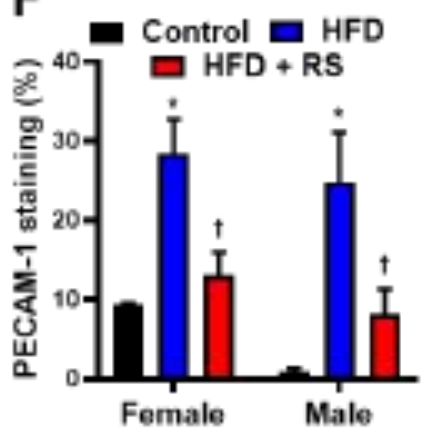

ApoE ${ }^{-/ *}$ HFD + RS
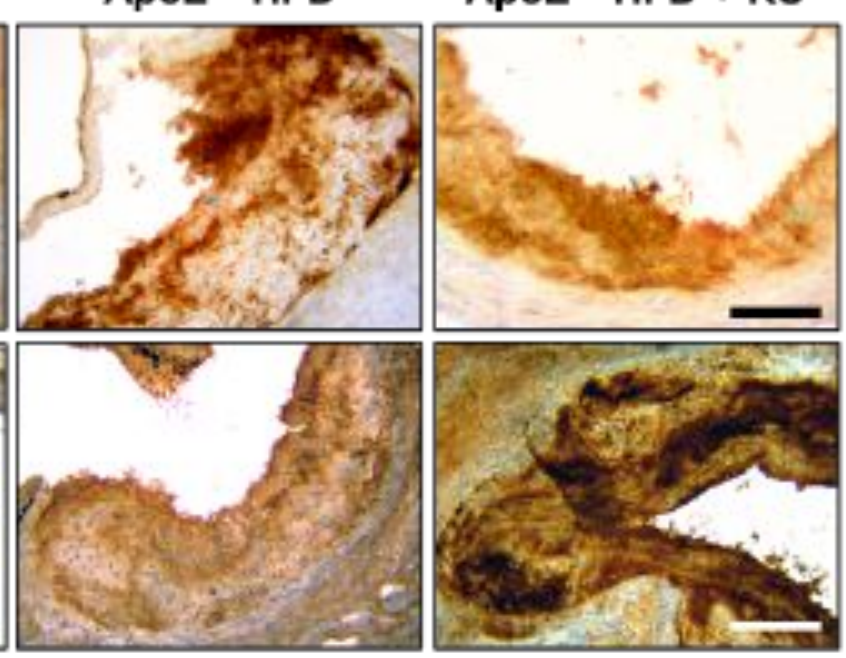

G

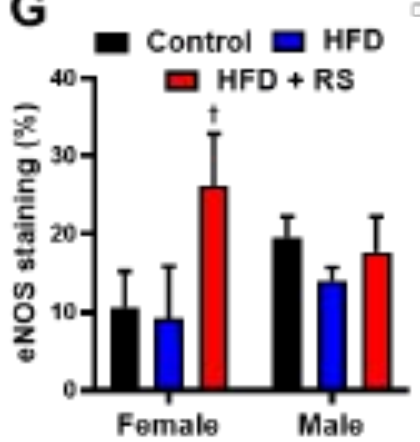

B

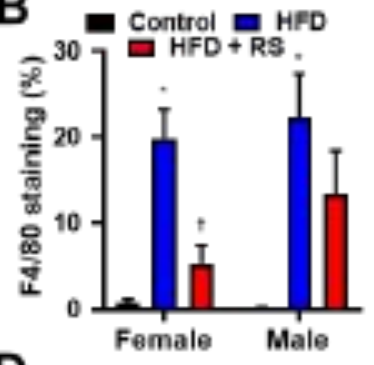

D - control $\square$ HFD

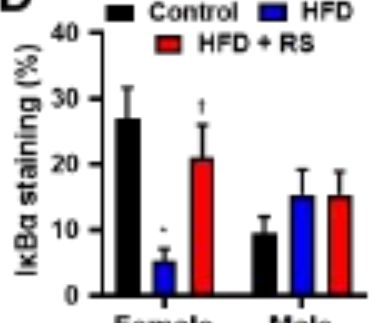

H

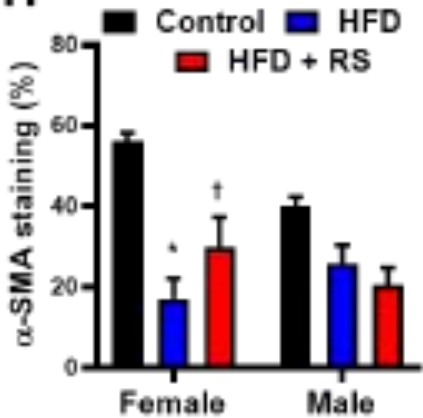


bioRxiv preprint doi: https://doi.org/10.1101/2022.02.10.479785; this version posted February 10,2022 . The copyright holder for this preprint (which was not certified by peer review) is the author/funder. All rights reserved. No reuse allowed without permission.

Supplemental Table 1. Primary Antibodies Used for Immunoblotting

\begin{tabular}{|c|c|c|c|c|}
\hline Target Protein & Company & Catalog \# & Species/lsotype & Dilution Ratio \\
\hline GAPDH & Cell Signaling & $2118 S$ & anti-rabbit & $1: 500$ \\
\hline a-SMA & Abcam & $a b 21027$ & anti-rabbit & $1: 500$ \\
\hline a-SMA (Су3) & Sigma-Aldrich & C6198 & Anti-mouse & $1: 200$ \\
\hline$\alpha$-Tubulin & Sigma-Aldrich & T9026 & anti-mouse & $1: 500$ \\
\hline$\beta$-Actin & Santa Cruz Biotech & sc-47778 & anti-mouse & $1: 500$ \\
\hline eNOS & Santa Cruz Biotech & sc-654 & Anti-rabbit & $1: 500$ \\
\hline $\mathrm{F} 4 / 80$ & Abcam & Ab6640 & anti-mouse & $1: 500$ \\
\hline FAK & Cell Signaling & $3285 S$ & Anti-rabbit & $1: 100$ \\
\hline Histone $\mathrm{H} 3$ & Cell Signaling & 9715S & anti-mouse & $1: 500$ \\
\hline $\operatorname{I\kappa B} \alpha$ & Cell Signaling & $4814 S$ & anti-rabbit & $1: 500$ \\
\hline $\mathrm{IKK} \alpha$ & Santa Cruz Biotech & sc-7606 & anti-mouse & $1: 500$ \\
\hline IKK $\beta$ & Cell Signaling & $2678 S$ & anti-rabbit & $1: 500$ \\
\hline NF-кBp65 & Thermo Fisher Scientific & PA1186 & anti-rabbit & $1: 500$ \\
\hline PECAM-1 & Cell Signaling & $3528 S$ & anti-mouse & $1: 500$ \\
\hline Phospho-IкB $\alpha$ (S32/34) & Thermo Fisher Scientific & MA515224 & anti-rabbit & $1: 500$ \\
\hline Phospho-IKK $\alpha / \beta$ & Cell Signaling & $2797 S$ & Anti-rabbit & $1: 500$ \\
\hline TKS5 & Sigma-Aldrich & $09-403$ & Anti-rabbit & $1: 100$ \\
\hline
\end{tabular}




\section{Supplemental Table 2. Rhamnan Sulfate Binding Affinity}

\begin{tabular}{cccc}
\hline Interaction & $\mathbf{k}_{\mathbf{a}}\left(\mathbf{m s}^{-1}\right)$ & $\mathbf{k}_{\mathrm{d}}\left(\mathbf{s}^{-1}\right)$ & $\mathbf{K}_{\mathbf{D}}(\mathbf{M})$ \\
\hline PDGF-BB to RS & $2.5 \times 10^{5}$ & $5.4 \times 10^{-3}$ & $2.8 \times 10^{-8}$ \\
& $\left( \pm 4.9 \times 10^{3}\right)$ & $\left( \pm 1.1 \times 10^{-3}\right)$ & \\
PDGF-BB to Heparin & $2.6 \times 10^{5}$ & $4.9 \times 10^{-3}$ & $1.9 \times 10^{-8}$ \\
& $\left( \pm 4.3 \times 10^{3}\right)$ & $\left( \pm 8.3 \times 10^{-5}\right)$ & \\
FGF-2 to RS & $3.0 \times 10^{5}$ & $7.7 \times 10^{-3}$ & $2.6 \times 10^{-8}$ \\
& $\left( \pm 6.0 \times 10^{3}\right)$ & $\left( \pm 8.1 \times 10^{-5}\right)$ & \\
FGF-2 to Heparin & $5.9 \times 10^{5}$ & $5.3 \times 10^{-3}$ & $9.0 \times 10$ \\
& $\left( \pm 1.4 \times 10^{4}\right)$ & $\left( \pm 8.1 \times 10^{-5}\right)$ & \\
NFKB p50 to RS & $1.8 \times 10^{4}$ & $1.9 \times 10^{-3}$ & $1.1 \times 10^{-7}$ \\
& $( \pm 721)$ & $\left( \pm 7.9 \times 10^{-5}\right)$ & \\
NFKB p50 to Heparin & $1.4 \times 10^{4}$ & $2.1 \times 10^{-3}$ & $1.5 \times 10^{-7}$ \\
& $( \pm 627)$ & $\left( \pm 8.4 \times 10^{-5}\right)$ & \\
NFKB p65 to RS & $4.8 \times 10^{5}$ & 0.011 & $2.3 \times 10^{-8}$ \\
& $\left( \pm 1.1 \times 10^{4}\right)$ & $\left( \pm 2.2 \times 10^{-4}\right)$ & \\
NFKB p65 to Heparin & $2.6 \times 10^{5}$ & 0.011 & $4.2 \times 10^{-8}$ \\
& $\left( \pm 5.2 \times 10^{5}\right)$ & $\left( \pm 3.4 \times 10^{-4}\right)$ & \\
\hline
\end{tabular}




\section{Supplemental Figure Legends}

Supplemental Figure 1. Dilution of (A) PDGF-BB and (B) FGF-2 were introduced on a sensor surface with RS and dissociation with HBS-EP buffer measured for three minutes. After three minutes, the surface was regenerated with $2 \mathrm{M} \mathrm{NaCl}$ and total response monitored in sensorgram $(n=5)$.

Supplemental Figure 2. Western blot analysis of cytosol fraction of p65 subunit of NF- $\kappa$ B. Cytosolic protein increased with $100 \mu \mathrm{g} / \mathrm{mL}$ RS dose but there was no change with other treatments $(\mathrm{n}=8) .{ }^{\dagger} p<0.05$ versus TNF- $\alpha$.

Supplemental Figure 3. Pharmacokinetics of RS in vivo. (A) Rhamnan sulfate concentration decreased after 4 hours in the abdominal aorta but accumulated in the thoracic aorta up to 24 hours after oral gavage $(n=2)$. (B) Concentration of RS in total blood plasma increased up to 12 hours and then started decreasing. In the liver, there was an initial influx of RS up to 4 hours after oral gavage and then steady accumulation after 12 hours. In the heart, RS concentration peaked at 4 hours after oral gavage $(n=2)$. (C) Following an intravenous injection, the decay constant of RS was calculated to be $0.0328 \mathrm{~min}^{-1}$ and a half-life of 21.13 minutes $(\mathrm{n}=3)$.

Supplemental Figure 4. Schematic representation of in vivo experiment for prevention of atherosclerosis.

Supplemental Figure 5. Plasma triglyceride concentration of $\mathrm{ApoE}^{-/-}$mice on HFD. Triglycerides in plasma of female mice increased with HFD but no change with RS treatment for both male and female mice $(n=10)$.

Supplemental Figure 6. Body and tissue weight of $\mathrm{ApoE}^{-/-}$mice on HFD and RS treatment. (A) Average weights of male and female mice increased over 13 weeks of HFD but there was no significant difference between HFD and HFD+RS groups $(n=10)$. (B) After 13 weeks, there was no significant change in weight in male and female mice with RS treatment $(n=10)$. (C) There was no difference in the ratio of average liver, gWAT or iWAT weight to total body weight in 
female mice $(n=10)$. (D) In male mice, gWAT to body weight ratio increased with RS treatment but there was no change in the liver or iWAT ratios $(\mathrm{n}=10) .{ }^{*} p<0.05$ versus HFD.

Supplemental Figure 7. Adipocytes in white adipose tissue are not affected by RS treatment. Histology sections of (A) gWAT and (B) iWAT from female mice were stained with hematoxylin and eosin. There was no change in size of adipocytes with HFD or RS treatment $(n=10)$. Scale bar $=200 \mu \mathrm{m}$. Sections of (C) gWAT and (D) iWAT from male mice were also stained with hematoxylin and eosin. There was no change in size of adipocytes with HFD or RS treatment ( $\mathrm{n}=$ 10). Scale bar $=200 \mu \mathrm{m}$.

Supplemental Figure 8. Blood velocity measured by ultrasound is decreased by $\mathrm{RS}$ in $\mathrm{ApoE}^{-/-}$ mice. After 12 weeks of HFD and RS, PSV, EDV and MV are lower compared to no treatment in ascending aortas of female mice while there was no change in blood velocity in aortic arches. Compared to no treatment, PSV and EDV were lower in descending aortas of female mice. In the carotid arteries, PSV, EDV and MV were lower compared to no treatment. In male mice, there was no change in blood velocity in the ascending aortas while only EDV was lower compared to the HFD group in the aortic arches. In the descending aortas of male mice, PSV, EDV and MV were lower compared to no treatment. There was no change in blood velocity in the carotid arteries of male mice $(\mathrm{n}=10) .{ }^{*} p<0.05$ versus HFD.

Supplemental Figure 9. Doppler ultrasound imaging to measure velocity of blood in aorta of ApoE ${ }^{-/-}$mice. (A) Images and velocity profiles of female $\mathrm{ApoE}^{-/-}$mice fed HFD and HFD+RS (n =10). (B) Images and velocity profiles of male ApoE ${ }^{-/-}$mice fed HFD and HFD+RS $(n=10)$.

Supplemental Figure 10. Doppler ultrasound imaging to measure velocity of blood in left common carotid artery of $\mathrm{ApoE}^{-/-}$mice. (A) Images and velocity profiles of female $\mathrm{ApoE}^{-/-}$mice fed HFD and HFD+RS $(n=10)$. (B) Images and velocity profiles of male ApoE ${ }^{-/-}$mice fed HFD and HFD+RS $(\mathrm{n}=10)$.

Supplemental Figure 11. Elasticity of aorta. Elasticity measured by circumferential strain is higher in female $\mathrm{ApoE}^{-/-}$mice treated with RS $(\mathrm{n}=10)$. 
Supplemental Figure 12. Immunohistochemical staining images of aortic arch from female mice. (A) Immunofluorescent images of NF- $\mathrm{BB} / \mathrm{p} 65$ staining from the three groups. Scale bar $=20 \mu \mathrm{m}$. Images of (B) PECAM-1 and (C) eNOS staining from the three groups. Scale bar $=100 \mu \mathrm{m}$. (D) Immunofluorescent images of $\alpha$-SMA staining from the three groups. Scale bar $=20 \mu \mathrm{m}$.

Supplemental Figure 13. Negative and positive controls of immunohistochemistry staining. Scale bar $=100 \mu \mathrm{m}$.

Supplemental Figure 14. Volcano plots for comparisons between the groups.

Supplemental Figure 15. Clustering analysis for the comparisons between the groups.

Supplemental Figure 16. Gene ontology analysis for (A) male or (B) female mice comparing HFD to HFD + RS groups. 


\section{Supplemental Figure 1}

A

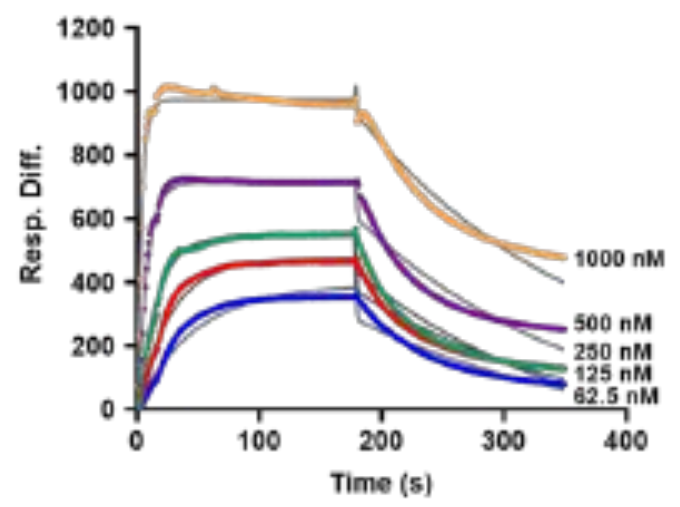

B

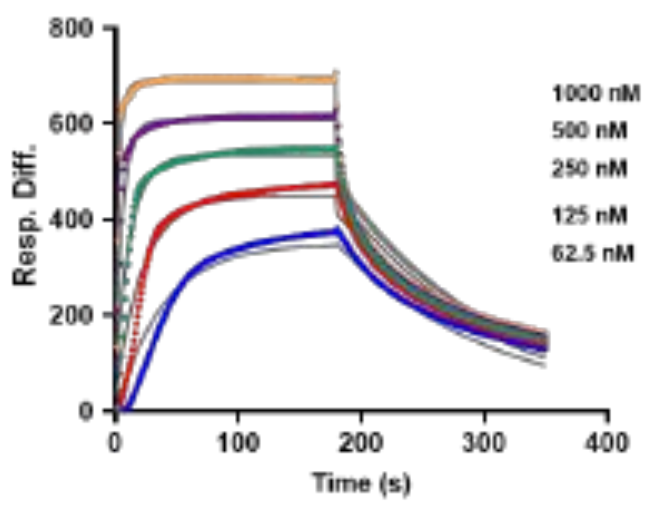


bioRxiv preprint doi: https://doi.org/10.1101/2022.02.10.479785; this version posted February 10, 2022. The copyright holder for this preprint (which was not certified by peer review) is the author/funder. All rights reserved. No reuse allowed without permission.

\section{Supplemental Figure 2}

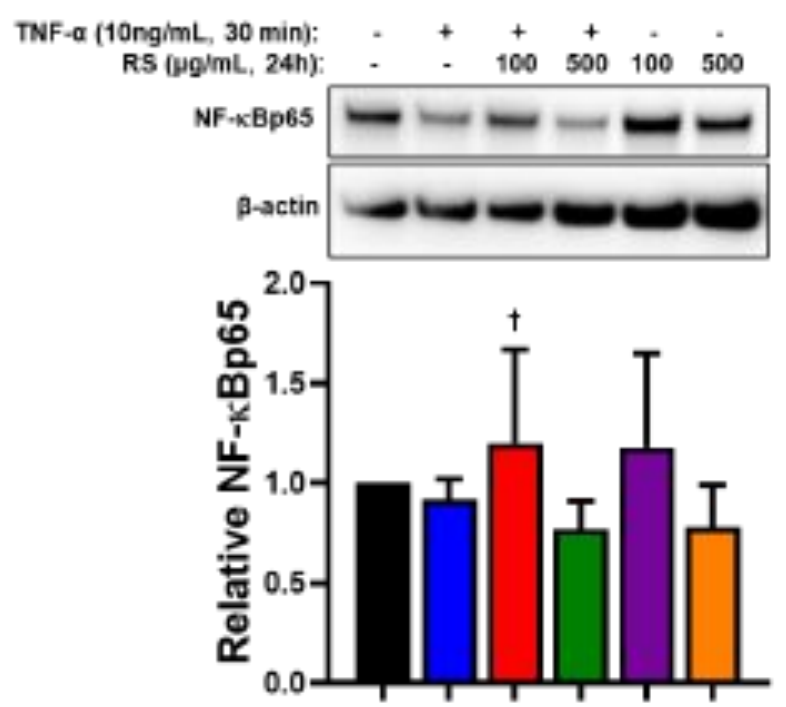

Page 38 of 53 


\section{Supplemental Figure 3}

A
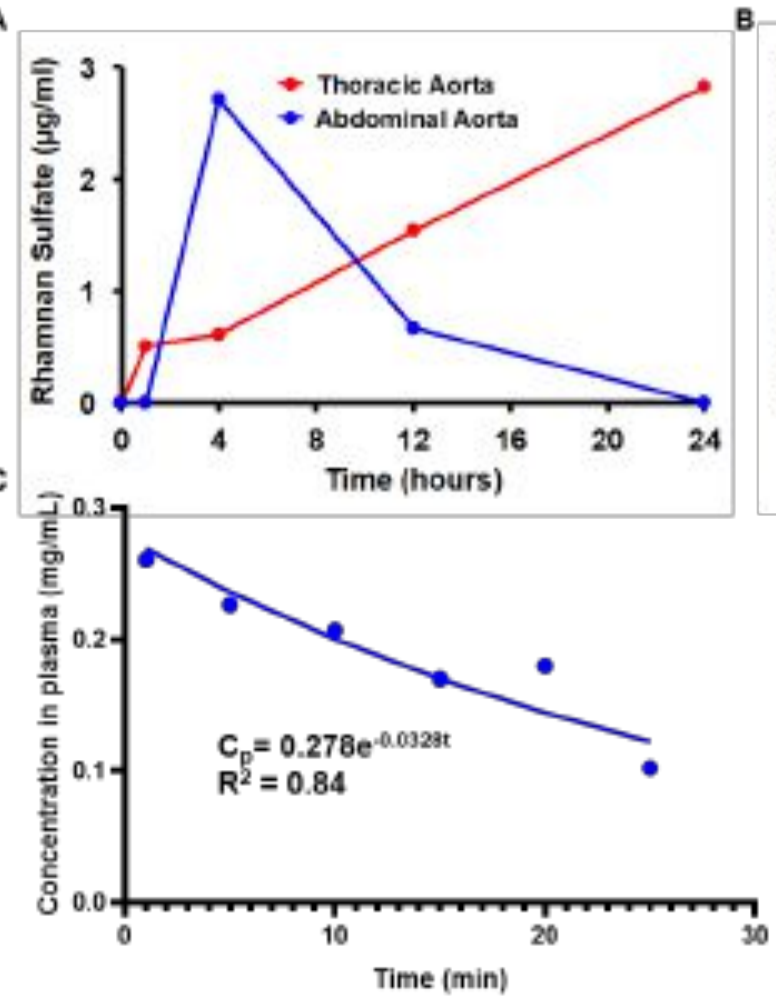

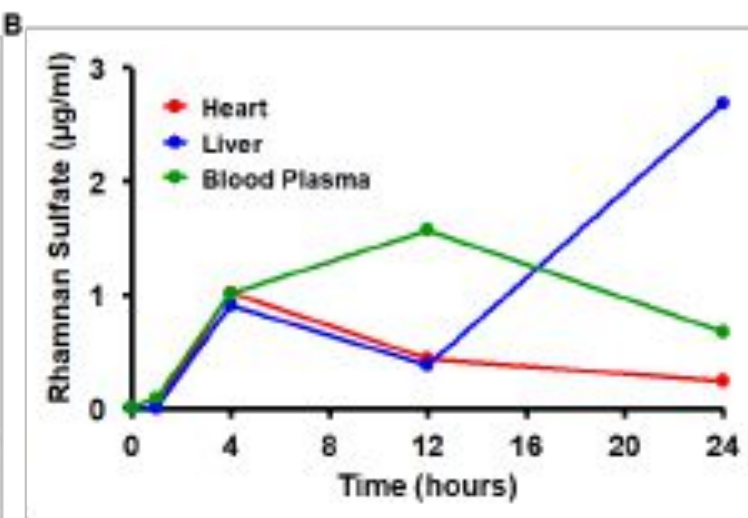




\section{Supplemental Figure 4}

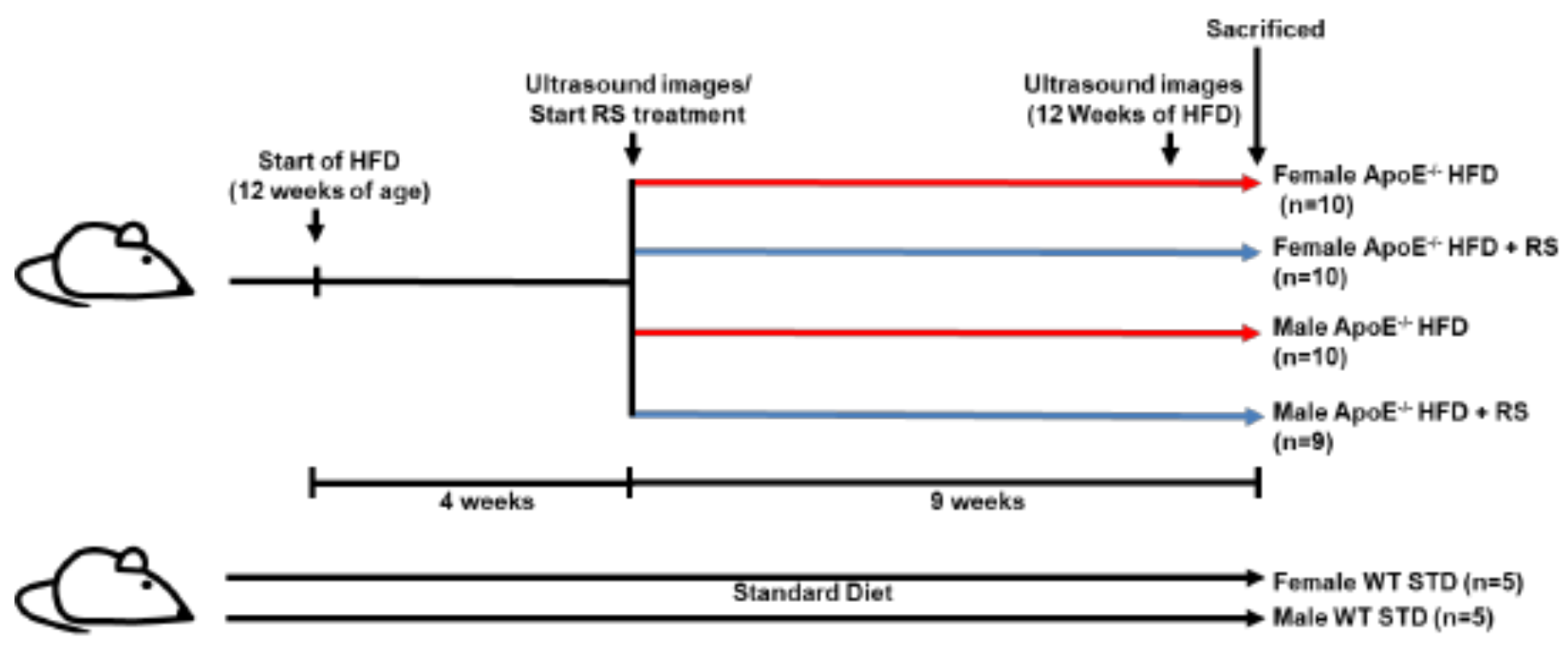




\section{Supplemental Figure 5}

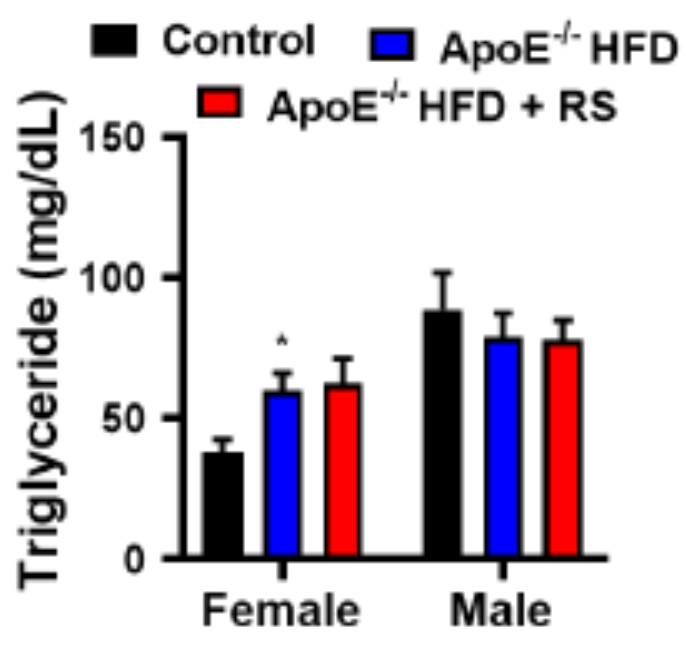

Page 41 of 53 


\section{Supplemental Figure 6}

A

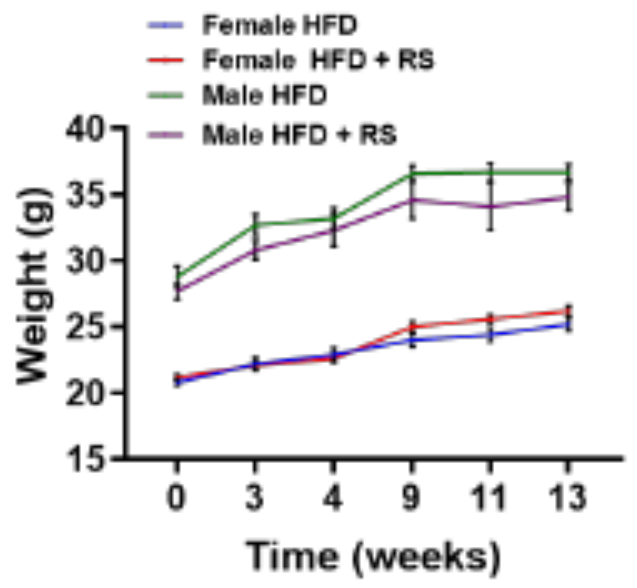

C

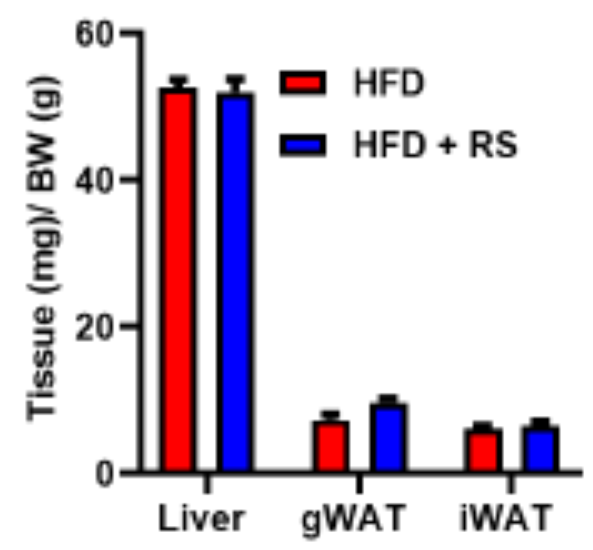

B
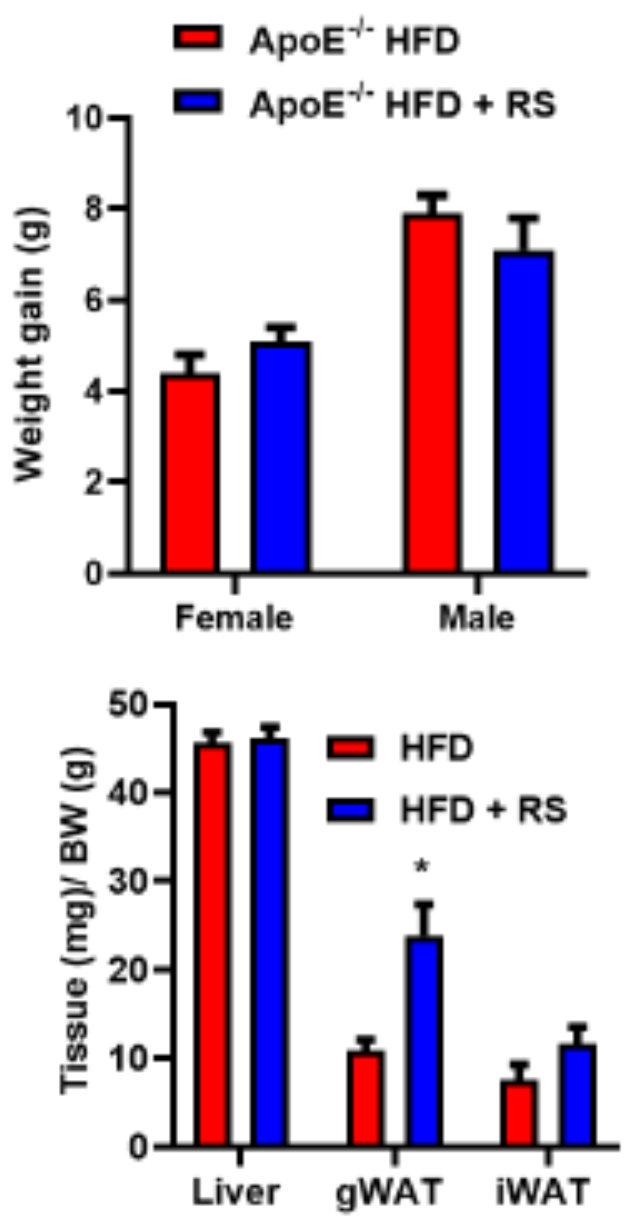


\section{Supplemental Figure 7}

A
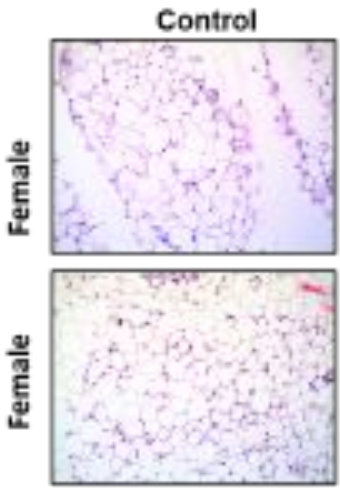

B
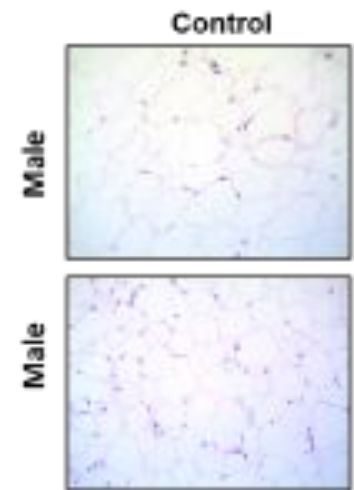

ApoE* HFD
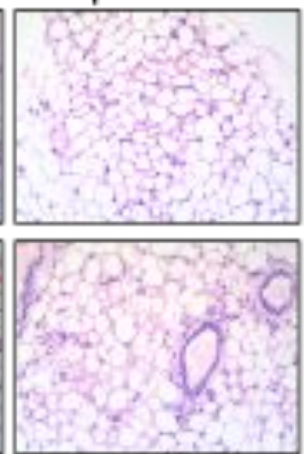

ApoE ${ }^{+}$HFD
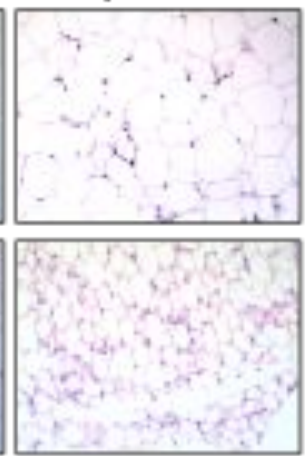

ApoE + HFD + RS
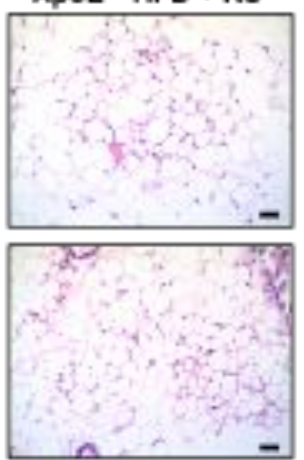

ApoE ${ }^{+}$HFD + RS
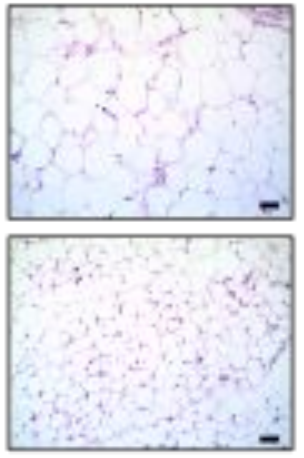

gWAT
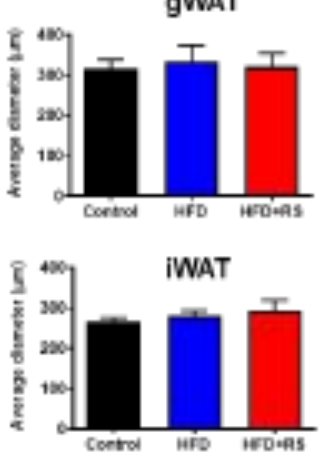

gWAT
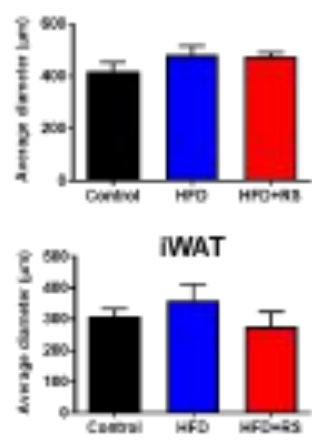


\section{Supplemental Figure 8}
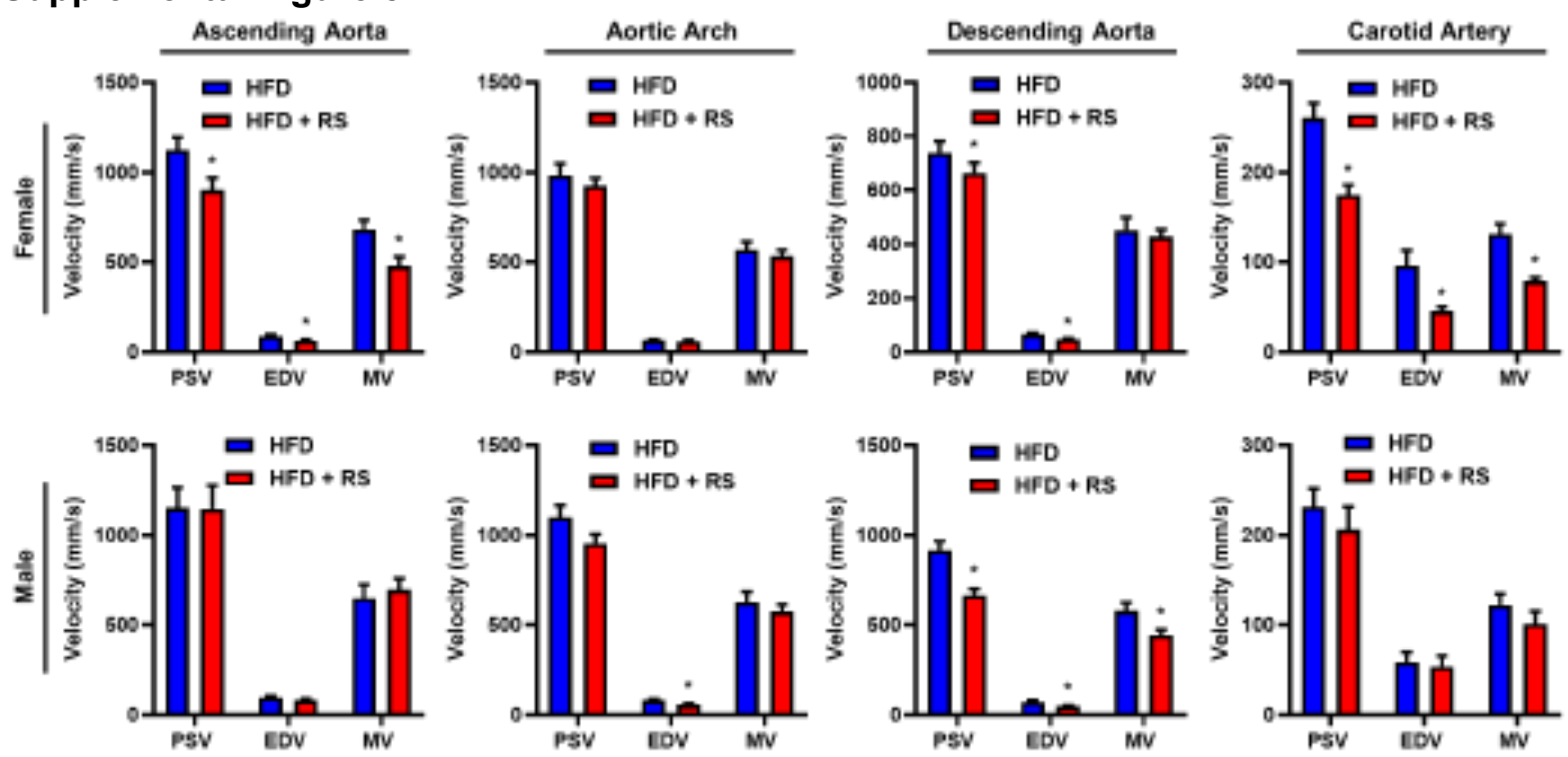


\section{Supplemental Figure 9}
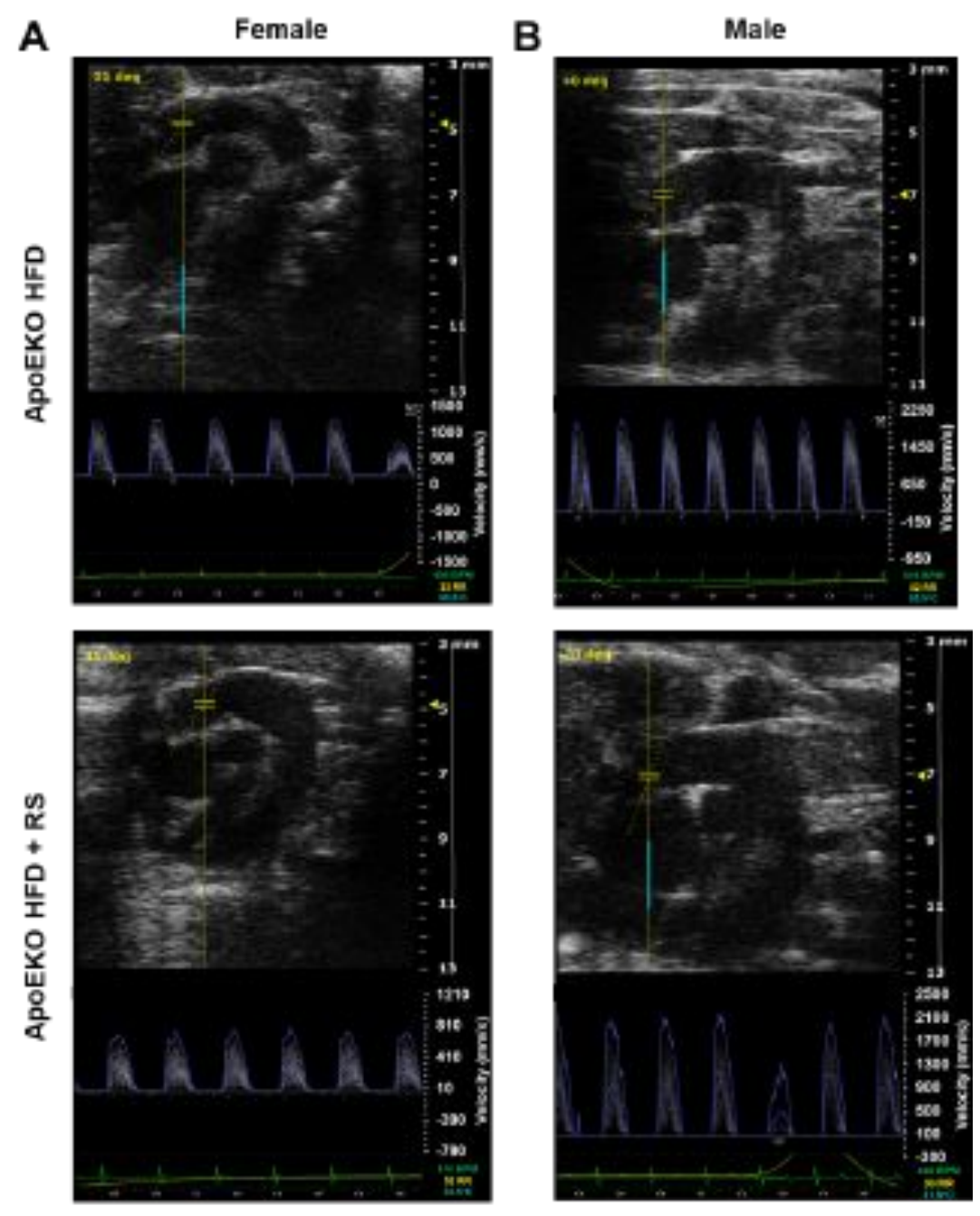
bioRxiv preprint doi: https://doi.org/10.1101/2022.02.10.479785; this version posted February 10, 2022. The copyright holder for this preprint (which was not certified by peer review) is the author/funder. All rights reserved. No reuse allowed without permission.

\section{Supplemental Figure 10}

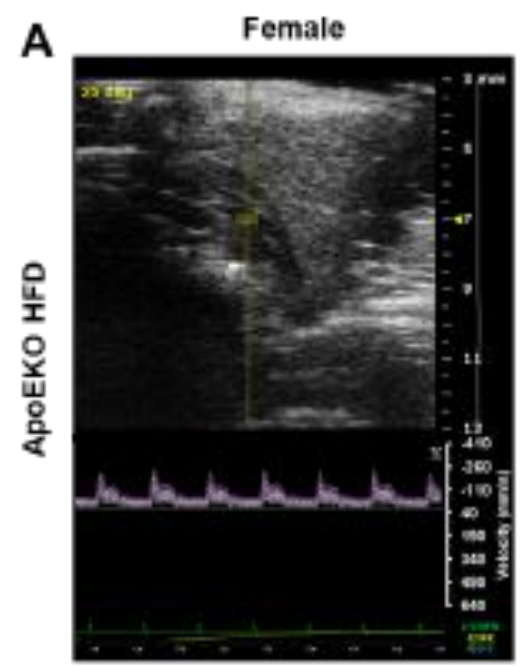

B
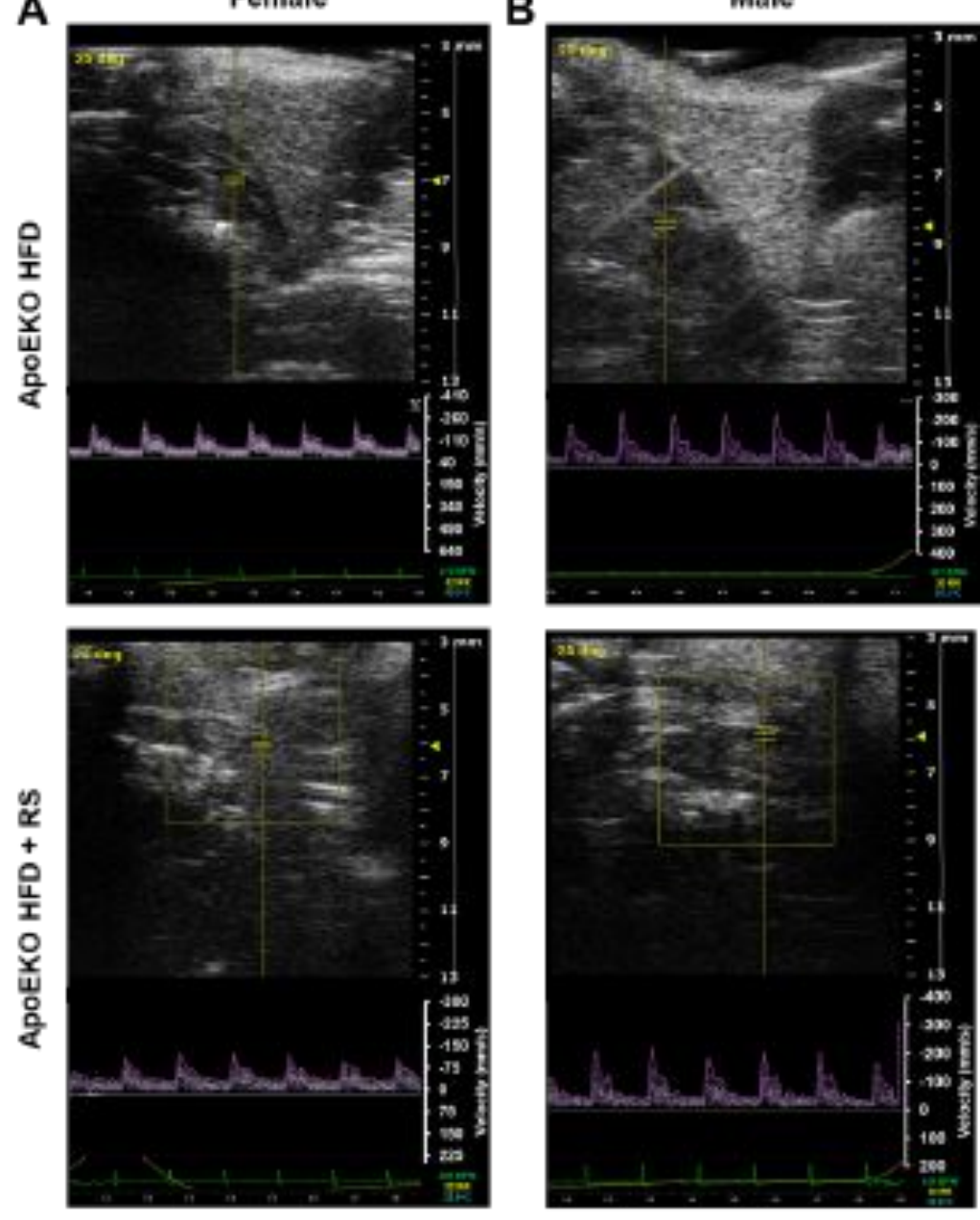


\section{Supplemental Figure 11}

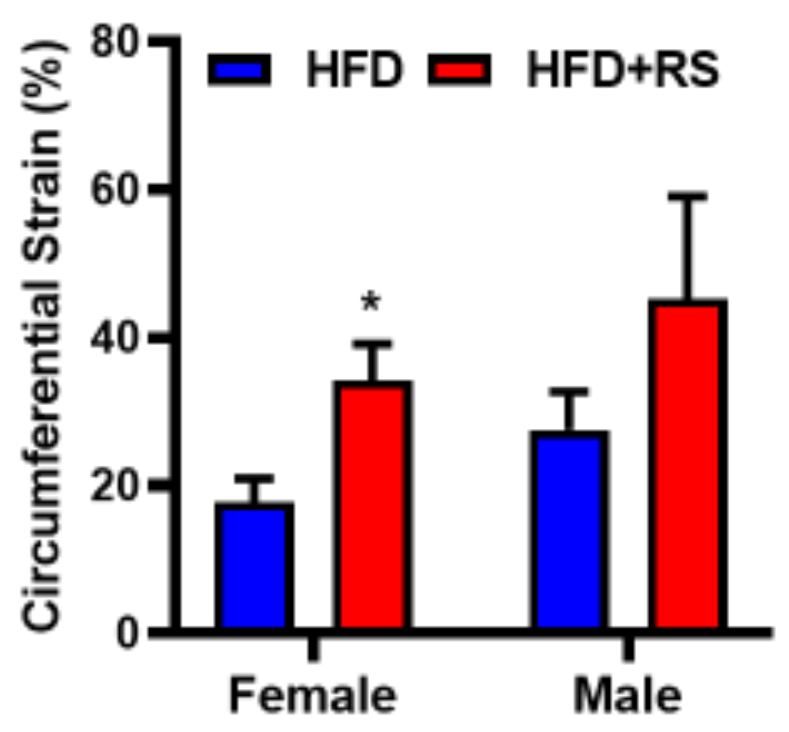




\section{Supplemental Figure 12}
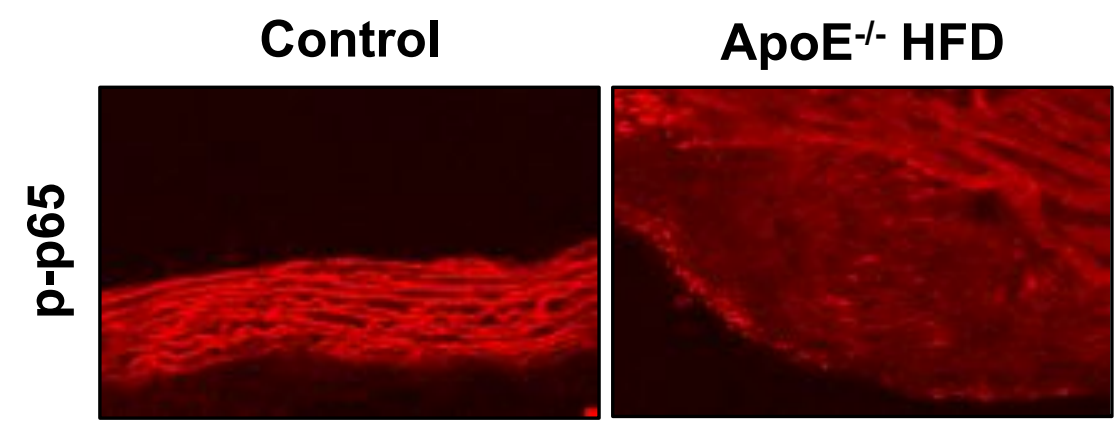

ApoE-/- HFD + RS
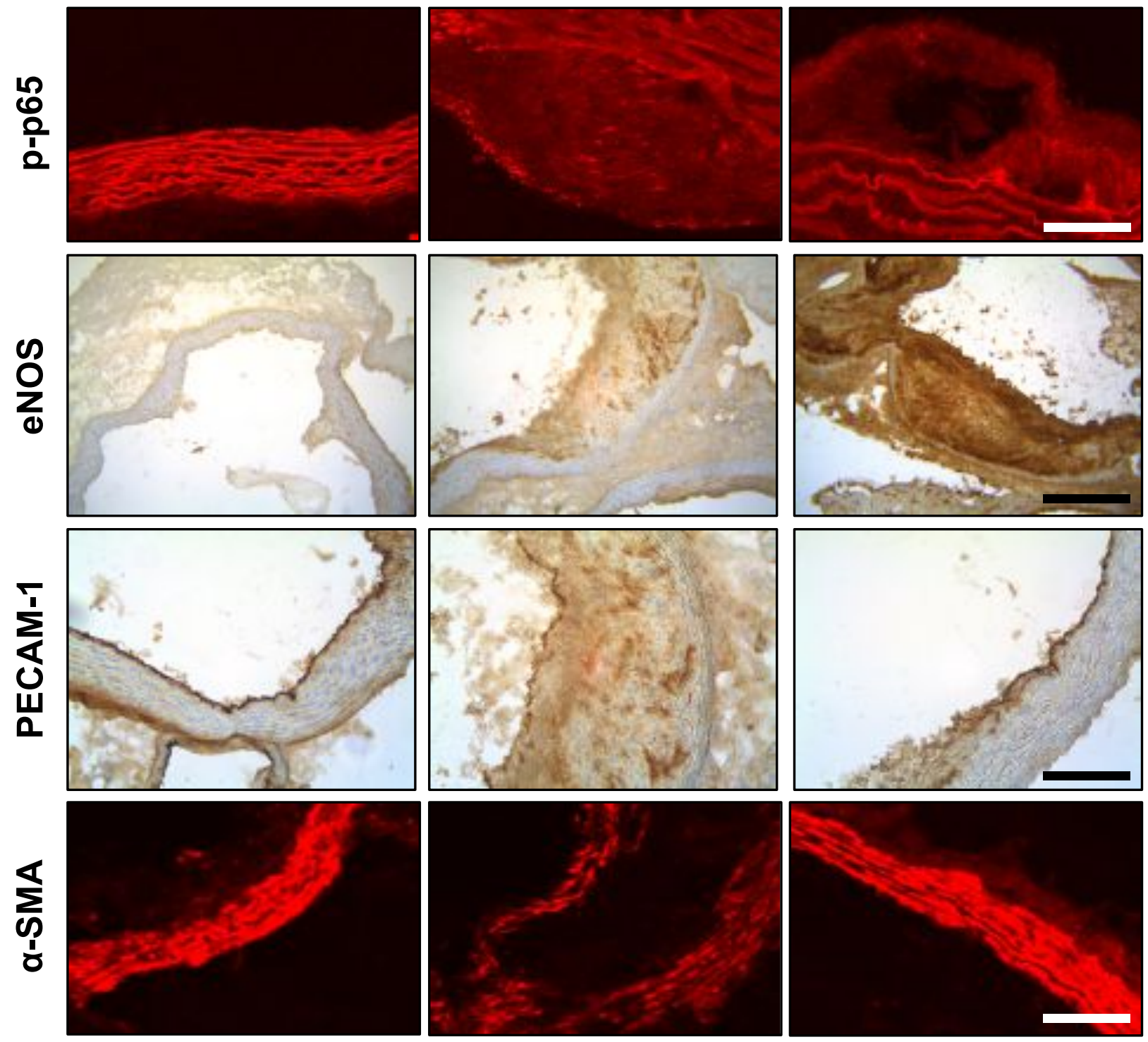


\section{Supplemental Figure 13}

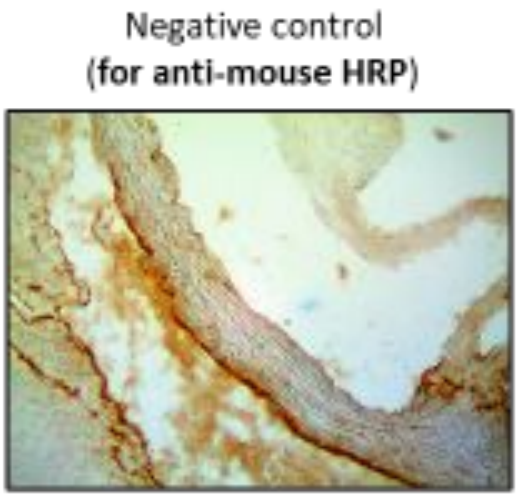

Negative control (for anti-rabbit HRP)

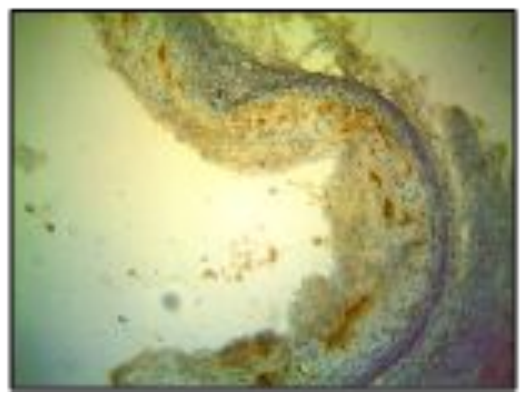

Positive control (F4/80)

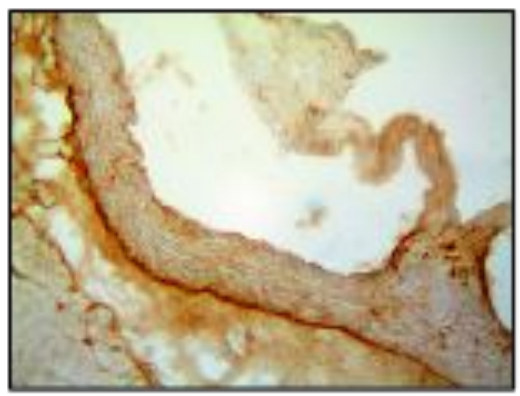

Positive control (IKB- $\boldsymbol{\alpha}$ )

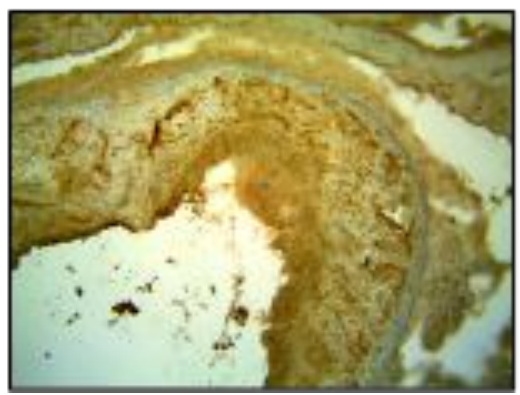

Positive control (PECAM1)

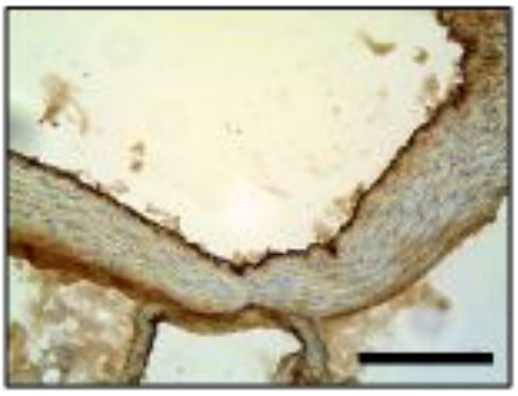

Positive control (eNOS)

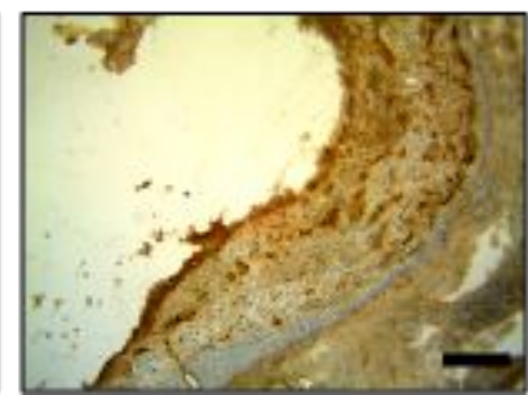




\section{References}

[1] H.C. Stary, A.B. Chandler, S. Glagov, J.R. Guyton, W. Insull, Jr., M.E. Rosenfeld, S.A. Schaffer, C.J. Schwartz, W.D. Wagner, R.W. Wissler, A definition of initial, fatty streak, and intermediate lesions of atherosclerosis. A report from the Committee on Vascular Lesions of the Council on Arteriosclerosis, American Heart Association, Circulation 89(5) (1994) 2462-78.

[2] L.B. Nielsen, Transfer of low density lipoprotein into the arterial wall and risk of atherosclerosis, Atherosclerosis 123(1-2) (1996) 1-15.

[3] R. Bitzur, H. Cohen, Y. Kamari, D. Harats, Intolerance to statins: mechanisms and management, Diabetes care 36(Supplement 2) (2013) S325-S330.

[4] N.C. Ward, G.F. Watts, R.H. Eckel, Statin toxicity: mechanistic insights and clinical implications, Circulation research 124(2) (2019) 328-350.

[5] S. Weinbaum, J.M. Tarbell, E.R. Damiano, The structure and function of the endothelial glycocalyx layer, Annu Rev Biomed Eng 9 (2007) 121-67.

[6] C.S. Alphonsus, R.N. Rodseth, The endothelial glycocalyx: a review of the vascular barrier, Anaesthesia 69(7) (2014) 777-84.

[7] B.M. van den Berg, H. Vink, J.A. Spaan, The endothelial glycocalyx protects against myocardial edema, Circulation research 92(6) (2003) 592-4.

[8] P.L. Voyvodic, D. Min, R. Liu, E. Williams, V. Chitalia, A.K. Dunn, A.B. Baker, Loss of syndecan-1 induces a pro-inflammatory phenotype in endothelial cells with a dysregulated response to atheroprotective flow, J Biol Chem 289(14) (2014) 9547-59.

[9] B.M. van den Berg, J.A. Spaan, H. Vink, Impaired glycocalyx barrier properties contribute to enhanced intimal low-density lipoprotein accumulation at the carotid artery bifurcation in mice, Pflugers Archiv : European journal of physiology 457(6) (2009) 1199-206.

[10] A.A. Constantinescu, H. Vink, J.A. Spaan, Endothelial cell glycocalyx modulates immobilization of leukocytes at the endothelial surface, Arteriosclerosis, thrombosis, and vascular biology 23(9) (2003) 1541-7.

[11] A.W. Mulivor, H.H. Lipowsky, Inflammation- and ischemia-induced shedding of venular glycocalyx, American journal of physiology. Heart and circulatory physiology 286(5) (2004) H1672-80.

[12] S. Devaraj, J.M. Yun, G. Adamson, J. Galvez, I. Jialal, C-reactive protein impairs the endothelial glycocalyx resulting in endothelial dysfunction, Cardiovascular research 84(3) (2009) 479-84.

[13] S.V. Lopez-Quintero, L.M. Cancel, A. Pierides, D. Antonetti, D.C. Spray, J.M. Tarbell, High glucose attenuates shear-induced changes in endothelial hydraulic conductivity by degrading the glycocalyx, PloS one 8(11) (2013) e78954.

[14] M. Gouverneur, B. Berg, M. Nieuwdorp, E. Stroes, H. Vink, Vasculoprotective properties of the endothelial glycocalyx: effects of fluid shear stress, J Intern Med 259(4) (2006) 393-400.

[15] T. Rademakers, K. Douma, T.M. Hackeng, M.J. Post, J.C. Sluimer, M.J. Daemen, E.A. Biessen, S. Heeneman, M.A. van Zandvoort, Plaque-associated vasa vasorum in aged 
apolipoprotein E-deficient mice exhibit proatherogenic functional features in vivo, Arteriosclerosis, thrombosis, and vascular biology 33(2) (2013) 249-56.

[16] B.M. van den Berg, J.A. Spaan, T.M. Rolf, H. Vink, Atherogenic region and diet diminish glycocalyx dimension and increase intima-to-media ratios at murine carotid artery bifurcation, American journal of physiology. Heart and circulatory physiology 290(2) (2006) H915-20.

[17] H. Vink, A.A. Constantinescu, J.A. Spaan, Oxidized lipoproteins degrade the endothelial surface layer : implications for platelet-endothelial cell adhesion, Circulation 101(13) (2000) 15002.

[18] E.P. Schmidt, Y. Yang, W.J. Janssen, A. Gandjeva, M.J. Perez, L. Barthel, R.L. Zemans, J.C. Bowman, D.E. Koyanagi, Z.X. Yunt, L.P. Smith, S.S. Cheng, K.H. Overdier, K.R. Thompson, M.W. Geraci, I.S. Douglas, D.B. Pearse, R.M. Tuder, The pulmonary endothelial glycocalyx regulates neutrophil adhesion and lung injury during experimental sepsis, Nat Med 18(8) (2012) 1217-23.

[19] M. Rehm, S. Zahler, M. Lotsch, U. Welsch, P. Conzen, M. Jacob, B.F. Becker, Endothelial glycocalyx as an additional barrier determining extravasation of $6 \%$ hydroxyethyl starch or $5 \%$ albumin solutions in the coronary vascular bed, Anesthesiology 100(5) (2004) 1211-23.

[20] A.W. Mulivor, H.H. Lipowsky, Role of glycocalyx in leukocyte-endothelial cell adhesion, Am J Physiol Heart Circ Physiol 283(4) (2002) H1282-91.

[21] P. Laurienzo, Marine polysaccharides in pharmaceutical applications: an overview, Mar Drugs 8(9) (2010) 2435-65.

[22] N.P. Patil, V. Le, A.D. Sligar, L. Mei, D. Chavarria, E.Y. Yang, A.B. Baker, Algal polysaccharides as therapeutic agents for atherosclerosis, Frontiers in cardiovascular medicine 5 (2018) 153.

[23] S. Patel, Therapeutic importance of sulfated polysaccharides from seaweeds: updating the recent findings, 3 Biotech 2(3) (2012) 171-185.

[24] N. Li, X. Liu, X. He, S. Wang, S. Cao, Z. Xia, H. Xian, L. Qin, W. Mao, Structure and anticoagulant property of a sulfated polysaccharide isolated from the green seaweed Monostroma angicava, Carbohydrate polymers 159 (2017) 195-206.

[25] T. Okamoto, N. Akita, M. Terasawa, T. Hayashi, K. Suzuki, Rhamnan sulfate extracted from Monostroma nitidum attenuates blood coagulation and inflammation of vascular endothelial cells, Journal of Natural Medicines 73(3) (2019) 614-619.

[26] L. Zang, Y. Shimada, T. Tanaka, N. Nishimura, Rhamnan sulphate from Monostroma nitidum attenuates hepatic steatosis by suppressing lipogenesis in a diet-induced obesity zebrafish model, Journal of Functional Foods 17 (2015) 364-370.

[27] X. Liu, S. Wang, S. Cao, X. He, L. Qin, M. He, Y. Yang, J. Hao, W. Mao, Structural characteristics and anticoagulant property in vitro and in vivo of a seaweed sulfated rhamnan, Marine drugs 16(7) (2018) 243.

[28] C.G. Glabe, P.K. Harty, S.D. Rosen, Preparation and properties of fluorescent polysaccharides, Analytical biochemistry 130(2) (1983) 287-294. 
[29] L.M. Cancel, J.M. Tarbell, The role of apoptosis in LDL transport through cultured endothelial cell monolayers, Atherosclerosis 208(2) (2010) 335-341.

[30] L.M. Cancel, A. Fitting, J.M. Tarbell, In vitro study of LDL transport under pressurized (convective) conditions, American Journal of Physiology-Heart and Circulatory Physiology 293(1) (2007) H126-H132.

[31] Y. Zeng, E.E. Ebong, B.M. Fu, J.M. Tarbell, The structural stability of the endothelial glycocalyx after enzymatic removal of glycosaminoglycans, PloS one 7(8) (2012).

[32] S. Pillarisetti, L. Paka, J.C. Obunike, L. Berglund, I.J. Goldberg, Subendothelial retention of lipoprotein (a). Evidence that reduced heparan sulfate promotes lipoprotein binding to subendothelial matrix, The Journal of clinical investigation 100(4) (1997) 867-874.

[33] X. Feng, A.J. Moy, H.T.M. Nguyen, J. Zhang, M.C. Fox, K.R. Sebastian, J.S. Reichenberg, M.K. Markey, J.W. Tunnell, Raman active components of skin cancer, Biomed Opt Express 8(6) (2017) 2835-2850.

[34] K. Kochan, E. Maslak, C. Krafft, R. Kostogrys, S. Chlopicki, M. Baranska, Raman spectroscopy analysis of lipid droplets content, distribution and saturation level in Non-Alcoholic Fatty Liver Disease in mice, Journal of biophotonics 8(7) (2015) 597-609.

[35] K. Kochan, K.M. Marzec, K. Chruszcz-Lipska, A. Jasztal, E. Maslak, H. Musiolik, S. Chłopicki, M. Baranska, Pathological changes in the biochemical profile of the liver in atherosclerosis and diabetes assessed by Raman spectroscopy, Analyst 138(14) (2013) 3885-3890.

[36] S.Y. Kim, F. Zhang, W. Gong, K. Chen, K. Xia, F. Liu, R. Gross, J.M. Wang, R.J. Linhardt, M.L. Cotten, Copper regulates the interactions of antimicrobial piscidin peptides from fish mast cells with formyl peptide receptors and heparin, Journal of Biological Chemistry 293(40) (2018) 15381-15396.

[37] A. Rudijanto, The role of vascular smooth muscle cells on the pathogenesis of atherosclerosis, Acta Med Indones 39(2) (2007) 86-93.

[38] L. Lamalice, F. Le Boeuf, J. Huot, Endothelial cell migration during angiogenesis, Circulation research 100(6) (2007) 782-794.

[39] M.A. Gimbrone Jr, G. García-Cardeña, Endothelial cell dysfunction and the pathobiology of atherosclerosis, Circulation research 118(4) (2016) 620-636.

[40] X.-H. Yu, X.-L. Zheng, C.-K. Tang, Nuclear Factor-кB Activation as a Pathological Mechanism of Lipid Metabolism and Atherosclerosis, 2015.

[41] R. Gareus, E. Kotsaki, S. Xanthoulea, I. van der Made, M.J. Gijbels, R. Kardakaris, A. Polykratis, G. Kollias, M.P. de Winther, M. Pasparakis, Endothelial cell-specific NF-kappaB inhibition protects mice from atherosclerosis, Cell Metab 8(5) (2008) 372-83.

[42] S. Kawashima, M. Yokoyama, Dysfunction of endothelial nitric oxide synthase and atherosclerosis, Arteriosclerosis, thrombosis, and vascular biology 24(6) (2004) 998-1005.

[43] F. Taylor, M.D. Huffman, A.F. Macedo, T.H. Moore, M. Burke, G. Davey Smith, K. Ward, S. Ebrahim, Statins for the primary prevention of cardiovascular disease, The Cochrane database of systematic reviews 1 (2013) CD004816. 
[44] T. Barzu, M. Pascal, M. Maman, C. Roque, F. Lafont, A. Rousselet, Entry and distribution of fluorescent antiproliferative heparin derivatives into rat vascular smooth muscle cells: comparison between heparin-sensitive and heparin-resistant cultures, J Cell Physiol 167(1) (1996) 8-21.

[45] K. Raman, C. Mencio, U.R. Desai, B. Kuberan, Sulfation patterns determine cellular internalization of heparin-like polysaccharides, Mol Pharm 10(4) (2013) 1442-9.

[46] T. Zaporozhets, N. Besednova, Prospects for the therapeutic application of sulfated polysaccharides of brown algae in diseases of the cardiovascular system, Pharmaceutical biology 54(12) (2016) 3126-3135.

[47] S. Hassan, S.A. El-Twab, M. Hetta, B. Mahmoud, Improvement of lipid profile and antioxidant of hypercholesterolemic albino rats by polysaccharides extracted from the green alga Ulva lactuca Linnaeus, Saudi journal of biological sciences 18(4) (2011) 333-340.

[48] E. Besterman, Effects of laminarin sulphate on experimental atherosclerosis and on serum lipids in rabbits during long-term intermittent cholesterol feeding, Atherosclerosis 12(1) (1970) 85-96. 